\title{
Emerging Fluorescent Molecular Tracers to Guide Intra-Operative Surgical Decision-Making
}

\author{
Pieterjan Debie and Sophie Hernot* \\ Laboratory for in vivo Cellular and Molecular Imaging (ICMI-BEFY/MIMA), Vrije Universiteit Brussel, Brussels, Belgium
}

\section{OPEN ACCESS}

Edited by:

Maria Cristina Bonferoni.

University of Pavia, Italy

Reviewed by:

Homan Kang,

Harvard Medical School,

United States

Mohamed Abdo Rizk,

Mansoura University, Egypt

*Correspondence:

Sophie Hernot

sophie.hernot@gmail.com

Specialty section:

This article was submitted to

Experimental Pharmacology and Drug

Discovery,

a section of the journal

Frontiers in Pharmacology

Received: 05 February 2019 Accepted: 24 April 2019

Published: 14 May 2019

Citation:

Debie P and Hernot S (2019) Emerging Fluorescent Molecular

Tracers to Guide Intra-Operative

Surgical Decision-Making.

Front. Pharmacol. 10:510

doi: 10.3389/fphar.2019.00510
Fluorescence imaging is an emerging technology that can provide real-time information about the operating field during cancer surgery. Non-specific fluorescent agents, used for the assessment of blood flow and sentinel lymph node detection, have so far dominated this field. However, over the last decade, several clinical studies have demonstrated the great potential of targeted fluorescent tracers to visualize tumor lesions in a more specific way. This has led to an exponential growth in the development of novel molecular fluorescent contrast agents. In this review, the design of fluorescent molecular tracers will be discussed, with particular attention for agents and approaches that are of interest for clinical translation.

Keywords: fluorescence-guided surgery, near-infrared fluorescence imaging, molecular imaging, intra-operative imaging, antibody-based fluorescent tracers

\section{INTRODUCTION}

Surgery, in combination with or without chemo and/or radiotherapy, remains the most recommended treatment with curative intent for many localized tumors. In these types of surgeries, the primary goal is to attain complete removal of all cancerous tissue and obtain negative tumor resection margins. By minimizing the risk of leaving cancer cells behind, chances of recurrence are diminished and overall survival is improved (Javidfar et al., 2016; Orosco et al., 2018; Tringale et al., 2018).

As visual inspection through the surgeon's eyes (open surgeries) or through color video (laparoscopic interventions) is often insufficient, a technique for the detection of occult tumor lesions, accurate and real-time definition of tumor margins, and assessment of the presence of locoregional LN metastases is warranted. Such a technique would be a major step forward in preventing over- and under- treatment, and personalizing the surgical treatment of many cancer patients (Hentzen et al., 2018).

A recent trend is the usage of fluorescence imaging during surgery, which is a real-time, sensitive, contact-free, relatively cheap, and non-ionizing technique that can easily be implemented within the surgical routine. Fluorescence imaging can provide anatomical, functional, or molecular information after administration of a fluorescent contrast agent, either through direct real-time imaging of the surgical field, or by intra-operative optical specimen mapping (Nagaya et al., 2017; Zhang et al., 2017b).

The application of fluorophores emitting in the near-infrared (NIR) region of the light spectrum is favored as they enable detection of signals up to several millimeters of depth under the tissue surface (Weissleder and Ntziachristos, 2003; Kovar et al., 2007). Indocyanine green (ICG) and methylene blue $(\mathrm{MB})$ are the only two NIR fluorescent dyes approved by the FDA, although the poor fluorescent properties of MB limit its use as fluorescent contrast agent (van Manen et al., 2018). 
ICG is a non-targeted hydrophobic dye that, once injected intravenously, aggregates to plasma proteins and is eliminated via the hepatobiliary route. Clinically-approved applications of ICG are determining cardiac output and hepatic function, and ophthalmic angiography (Soons et al., 1991; Iijima et al., 1997; Stanga et al., 2003). A broader range of applications has since been investigated, going from the use of ICG in reconstructive surgery for assessment of tissue perfusion (Holm, 2010), to sentinel lymph node mapping (Aoun et al., 2017; Chand et al., 2018), ureter visualization (Siddighi et al., 2014), and in some cases, tumor imaging (Van Der Vorst et al., 2013; Liberale et al., 2017; Nakaseko et al., 2018). ICG tumor uptake is reliant on the enhanced permeability and retention (EPR) effect, which, while effective in mouse models, has seen only limited applicability in the human situation due to differences in tumor growth and development (Nichols and Bae, 2014; Danhier, 2016), and has been demonstrated to lead to false-positive results for imageguided surgery (Tummers et al., 2015).

As fluorescent dyes by themselves generally lack tumor specificity, molecular targeted fluorescent agents have been introduced. Targeted tracers consist of a fluorophore chemically conjugated to a targeting moiety, the latter possessing binding affinity for a specific cancer-associated molecular target or biomarker. Targeted tracers that are always fluorescent, are referred to as "always-on" targeted tracers. In this review the different parameters to the design of these tracers will be discussed, from the level of target selection, to the choice of targeting moiety, fluorophore, and conjugation strategy. Alternatively, probes can be designed around mechanisms that cause fluorescence to be quenched until activation. This can be used for the development of "activatable" or "smart" fluorescent probes. An overview of the different types of activatable tracers will also be provided.

\section{MOLECULAR-TARGETED FLUORESCENT TRACERS}

\section{Conjugatable NIR Fluorophores}

In fluorescence image-guided surgery (FIGS) research and practice, fluorophores operating in the NIR region are most often used, because of superior imaging characteristics compared to light in the visible spectrum. More specifically, the lower background and improved tissue penetration -a consequence of diminished scattering, endogenous fluorophore absorption and autofluorescence- makes NIR light more suited (Weissleder and Ntziachristos, 2003; Kovar et al., 2007). The NIR domain applicable for in vivo optical imaging can actually be separated in two distinct areas: the NIR-I (650-900 nm) and NIR-II window $(1,000-1,700 \mathrm{~nm})$.

\section{The NIR-I Window}

In the NIR-I region, a wide choice of fluorophores is available for conjugation. Appropriate fluorophores should be (photo)stable in vitro and in vivo, be soluble in aqueous environments, and their extinction coefficient and quantum yield should be as high as possible to maximize brightness. For the labeling of proteins and small molecule ligands for FIGS, cyanine-based fluorescent dyes are by far the most widely investigated (Figure 1A). Cyanine dyes typically consist of two heterocyclic nitrogen-containing rings connected by a polymethine bridge. Extension of the polymethine bridge to penta- and heptamethines, red-shifts the absorption and emission of the dyes (Yi et al., 2014; Zhang et al., 2017b). In comparison to ICG, the most commonly used cyanine dyes have been rendered less hydrophobic by the inclusion of several charged groups such as sulfonic acids (e.g., sulfo-Cy5, sulfo-Cy7) in their structure resulting in less non-specific protein interactions in vivo (Mujumdar et al., 1993). In the synthesis of heptamethine dyes, it has been found that the length of the polymethine chain has a negative effect on the chemical stability, as well as the photochemical properties of the dye. This has resulted in the integration of a central cyclohexenyl ring into the structure, which improves stability and fluorescence quantum yield through the increased rigidity of the molecular structure (Tarazi et al., 1998).

IRDye800CW (Figure 1A) is the most applied dye for the design of targeted FIGS tracers. IRDye800CW is primarily cleared via the kidneys when intravenously injected, with some liver uptake, though much less than for ICG (Marshall et al., 2010). An alternative development was that of the zwitterionic dye ZW800-1 (Figure 1A). Due to balanced surface charges on its structure, this fluorophore interacts very little with serum proteins, and is almost exclusively cleared by the kidneys (Choi et al., 2011). However, the ether linkage on the meso carbon at the core of this dye has been found to be unstable in vivo, leading to a decrease of the fluorescent signal over time. This issue was resolved by replacing this ether linkage with a carboncarbon bond (Hyun et al., 2014). Yet, this modification comes at the cost of increased formation of $\mathrm{H}$-dimers, which are caused by stacking of the fluorophores (Ogawa et al., 2009). Both IRDye800CW and ZW800-1 have, due to their renal clearance, also been proposed for ureter imaging (Choi et al., 2011; Korb et al., 2015).

Other cyanine dyes that have been investigated (pre)clinically for FIGS include the pentamethine dyes BM104, Dy676, IRdye650, IRDye680RD, and Alexa Fluor 680 (AF680), and the heptamethine dyes FNIR-Z-759, Xenolight 770CF, S0456, LS288, and ZWCC. Even ICG is sometimes used as a conjugatable fluorophore in always-on targeted tracers (Juhl et al., 2016), though it is most often incorporated in activatable targeted tracers, as aggregation of the dye to the structure of the targeting moiety will cause quenching, until the tracer is metabolized (Kobayashi et al., 2016). It is possible to use NIR dyes based on other backbones, such as BODIPYs, squaraines, rhodamines and porphyrins, however, these are not often used for FIGS, given their either excessive hydrophobicity or poor photochemical properties (Zhang et al., 2017b). The spectral properties of the chosen dye are however interdependent with the excitation light source and emission collection specifications of the camera system used during imaging.

\section{The NIR-II Window}

Imaging in the NIR-II window has further advantages related to autofluorescence and scattering compared to the NIR-I window, though absorption by water is slightly higher at these 


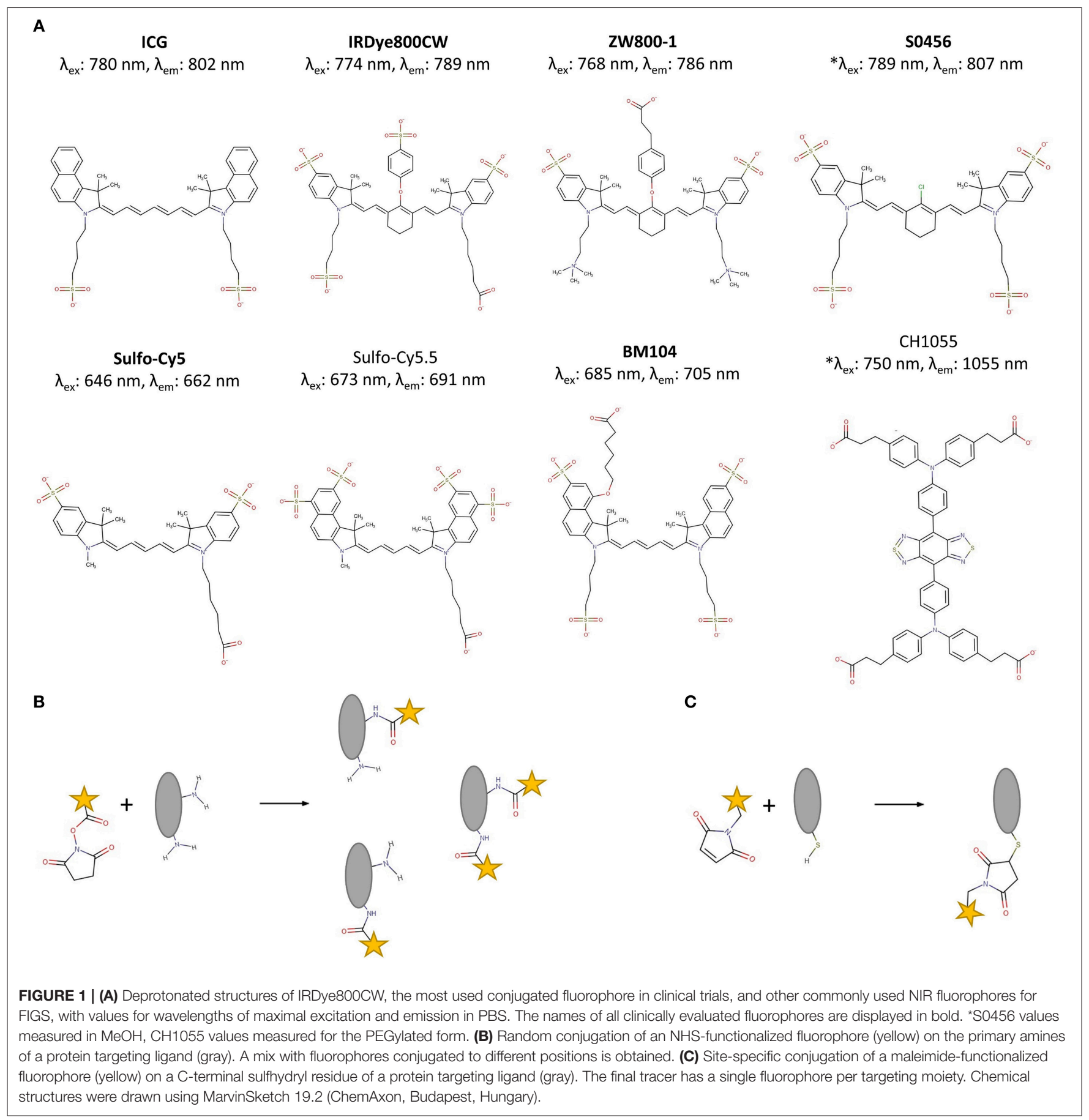

wavelengths. NIR-II imaging, however, is difficult due to low quantum yields, poor water solubility and general lack of availability of biocompatible fluorophores (Hong et al., 2017). Only recently, Antaris et al. described the synthesis of the biocompatible and renally cleared NIR-II organic fluorophore CH1055 (Figure 1A) and its use for targeted tumor imaging after conjugation with an anti-Epidermal Growth Factor Receptor (EGFR) affibody-molecule (Antaris et al., 2016). This field may gain more traction in the near future (Jin, 2019).

\section{Hybrid Nuclear and Fluorescent Labels}

While the use of NIR fluorescent dyes has led to increased signal-to-background ratios and better overall depth penetration up to several millimeter in tissue, deeper lying, and hidden lesions would still be missed. To this end, the combination of NIR fluorescence and nuclear techniques in a single tracer may be attractive. The nuclear component can be used for preoperative imaging, as well as for intra-operative guidance using a gamma-detecting probe (coarse navigation), at which point, 
fluorescence would provide high resolution visual guidance for precise resection (Van Leeuwen et al., 2016). Integration of both modalities onto a tracer can occur in several ways. Conjugation of the fluorophore and chelator for radioactive labeling at different positions is one option, either through coor sequential incubation of the targeting ligand with the chosen fluorophore and chelator (Lütje et al., 2014b). Several preclinical hybrid single photon emission tomography (SPECT)/fluorescent tracers combining IRDye800CW and ${ }^{111}$ In have been prepared in this manner, including the antibodies BIWA against CD44v6 (Odenthal et al., 2018) (Figure 3A), MN-14 and Labetuzumab against carcinoembryonic antigen (CEA) (Rijpkema et al., 2014; Hekman et al., 2017), and D2B against prostate specific membrane antigen (PSMA) (Lütje et al., 2014a). This technique has also been applied clinically, with the carbonic anhydrase 9 (CAIX) specific antibody Girentuximab (Hekman et al., 2016, 2018). The same manner of conjugation was used to prepare preclinical positron emission tomography (PET)/NIR tracers by labeling the anti-CD146 antibody YY146 with IRDye800CW and ${ }^{89} \mathrm{Zr}$ (Hernandez et al., 2016), the anti-prostate stem cell antigen (PSCA) minibody A11cMb with a Cy5.5 dye and ${ }^{89} \mathrm{Zr} /{ }^{124} \mathrm{I}$ (Tsai et al., 2018), or the anti-prostate stem cell antigen (PSCA) diabody A2cDb with IRDye800CW and ${ }^{124}$ I (Zettlitz et al., 2018).

In another integration strategy, the fluorophore and the radiolabel can be combined into a single structure. This is advantageous since a more homogenous tracer is obtained, whose biodistribution can be accurately determined via radioactivity. Furthermore, this is often the only possibility when working with small peptides or molecules, as multiple attachment points may not be available. However, such structures are more complex to design, as opposed to the more straightforward separate labeling procedure. A urokinase-type plasminogen activator receptor (uPAR) specific antibody, called ATN-658, was conjugated with both ZW800-1 and a chelator for ${ }^{111}$ In labeling through a single structure called a "multifunctional single attachment point" (MSAP) that bore both labels (Boonstra et al., 2015c, 2017). The MSAP-strategy was also used to combine an ${ }^{111} \mathrm{In} /$ chelator complex and Cy5.5 fluorophore for conjugation to either an integrin binding RGD peptide or the anti-TZ14011 peptide targeting chemokine receptor 4 (CXCR4) (Kuil et al., 2011; Buckle et al., 2013). Additional dual labeling structures have been explored, for example, the construction of a dual-modality linker combining Cy5 and ${ }^{18} \mathrm{~F}$ on the diabody $\mathrm{A} 2 \mathrm{cDb}$ (Zettlitz et al., 2019), or for the preparation of a CH1055- ${ }^{68} \mathrm{Ga}-\mathrm{RGD}$ tracer (Sun et al., 2018), ${ }^{68} \mathrm{Ga}$-IRDye650/IRDye800CW conjugated bombesin antagonists (Zhang et al., 2017a; Li et al., 2018), or a Cy5labeled anti-PSMA KuE peptide with a chelator for ${ }^{68} \mathrm{Ga}$ or ${ }^{177} \mathrm{Lu}$ labeling for PET or SPECT/targeted radionuclide therapy (TRNT), respectively (Schottelius et al., 2018).

\section{Labeling Strategies}

Fluorophores (and by extension, hybrid labels) can be linked to the targeting moiety using a range of different conjugation chemistries. As opposed to small molecules and peptides that are generally more tolerant toward harsher conditions such as the use of organic solvents and high temperatures, the conjugation of fluorophores to larger protein-based moieties is restricted to softer conditions. The most commonly applied strategy to this end is the formation of an amide bond between primary amines, and an activated carboxylic acid (often activated via a N-hydroxysuccinimide (NHS)-ester, Figure 1B) (Toseland, 2013). While every polypeptide contains a primary amine at its $\mathrm{N}$-terminus, this method is often applied for random conjugation on lysine residues. In larger protein structures, the abundancy of accessible lysines makes the degree of conjugation and the exact positioning of fluorophores difficult to control, resulting in a heterogenous tracer mixture. Furthermore, having many fluorophores per targeting ligand can lead to selfquenching effects (reduced brightness) and if the fluorophores are conjugated in or close to the antigen-binding region, they may negatively impact the binding capacities of the tracer (Debie et al., 2017). This can especially be a problem for smaller compounds, though it has been demonstrated that even the binding efficiency of full antibodies can be affected (Vira et al., 2010; Szabó et al., 2018).

Site-specific labeling methods resulting in homogenous tracer preparations in which the fluorophore is only attached to a specific, pre-determined location situated away from the antigeninteraction site, may offer a solution. The formation of a thioether bond between a sulfhydryl residue and a maleimide functionalized fluorophore is an often-employed strategy in FIGS (Figure 1C). To this end, a free cysteine residue is incorporated in the targeting moiety's structure at the location of predilection, such as the C- or N-terminus of protein scaffolds, peptides and small antibody fragments (Sun et al., 2005; Massa et al., 2014). Antibodies and larger fragments such as minibodies and diabodies can furthermore be partially reduced, freeing the sulfhydryl residues of more exposed disulfide bridges for conjugation (Olafsen et al., 2004; Sonn et al., 2016; Tsai et al., 2018; Zettlitz et al., 2018; Zhang et al., 2018). Many other site-specific methods have gained popularity over the last years, such as the azide-alkyne cycloaddition-click chemistry (Li et al., 2014), enzymatic modification of peptide tags (e.g., transglutaminase-, sortase-, or intein-mediated conjugation) (Massa et al., 2016a), incorporation of unnatural amino acids for biorthogonal conjugation or the use of linking peptides such as the SPY/SPYcatcher method (Massa et al., 2016b; Alam et al., 2018). While these techniques are promising for the future development of FIGS tracers, to date, they have not yet been applied in clinical tracers, and have seen only limited development in preclinical FIGS research.

\section{Impact of Fluorophore and Conjugation on the Tracer's Pharmacokinetics}

Conjugation of a fluorescent dye to a targeting ligand can possibly alter the pharmacokinetics of the ligand. The physicochemical properties of the dye (e.g., hydrophilicity and global/local charge distributions), the degree of conjugation, as well as the chosen conjugation method all play a role in the general biodistribution of the FIGS tracer. It has been observed that after labeling with IRDye800CW, tracers most often exhibit more extensive non-specific targeting in vivo, including higher liver uptake. This is likely caused by the interaction of IRDye800CW with 


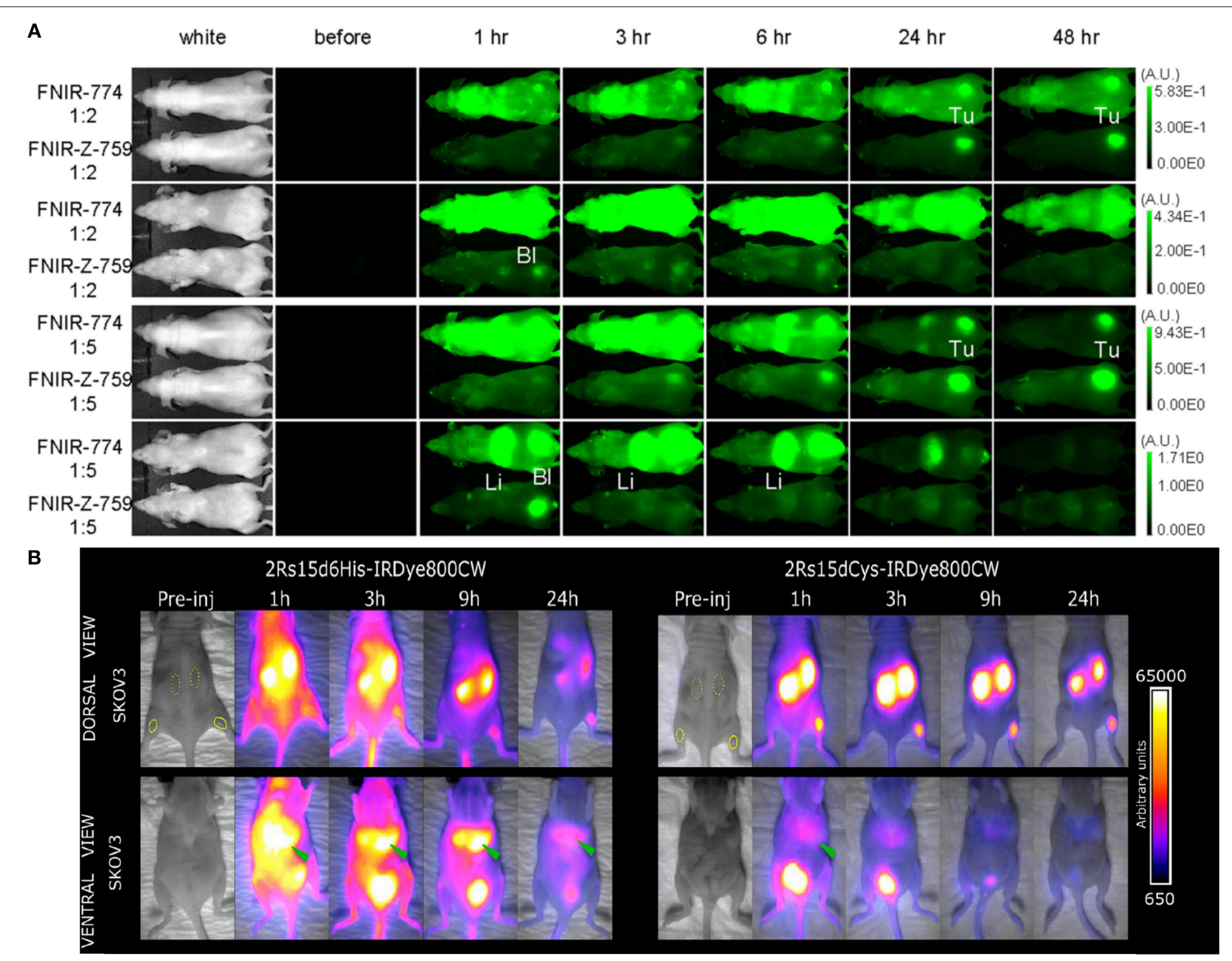

FIGURE 2 | Examples of the influence of the fluorescent dye and conjugation strategy on the pharmacokinetic profile of tracers. (A) Dorsal and ventral images of the in vivo biodistribution of panitumumab randomly conjugated (2:1 or 5:1 fluorophore vs. antibody ratio) with a highly negatively charged (FNIR-Z-774) or zwitterionic (FNIR-Z-759) fluorophore. The zwitterionic fluorophore promotes renal elimination and faster clearance, while the negatively charged fluorophore causes hepatic clearance and higher background fluorescence. Adapted with permission from Sato et al. (2016b). Copyright (2016) American Chemical Society. (B) Dorsal and ventral images of biodistribution of anti-HER2 nanobody 2Rs15d either randomly or site-specifically conjugated to IRDye800CW. Random conjugation promotes increased hepatic clearance and higher background fluorescence of the tracer, as opposed to the site-specifically conjugated nanobody that was mainly renally cleared. Adapted with permission from Debie et al. (2017). Copyright (2017) American Chemical Society.

serum proteins. Further hepatic metabolization of the tracer can in addition be a source of intestinal background signal which could be contrast-limiting in abdominal applications (Choi et al., 2011, 2013; Debie et al., 2017). This is in accordance with findings for other heptamethine fluorophores, where a high number of negative charges on the fluorophore -as is the case for IRDye800CW- are seen to cause partial hepatobiliary clearance (Sato et al., 2016b) (Figure 2A). Other than merely causing increased background signals, interaction with serum proteins will furthermore cause a change in the imaging window of the tracer. While this effect is already observed for long-circulating antibodies (Sato et al., 2016b; Cilliers et al., 2017), the impact on smaller compounds that usually show fast pharmacokinetics and renal clearance can be considerably more pronounced, in some cases delaying the optimal imaging window from a few hours to up to a day or longer. Indeed, increased liver uptake and delayed optimal tumor-to-background ratios (TBR) were observed for randomly IRDye800CW conjugated nanobodies (Figure 2B), scFv's, Fab fragments and diabodies (Yang et al., 2014; Boonstra et al., 2015b; Debie et al., 2017; El-Sayed et al., 2018; Boogerd et al., 2019). Interestingly, the gravity of this effect has been found to also be related to the used conjugation chemistry. For instance, we found that the pharmacokinetics of site-specifically IRDye800CW or IRDye680RD conjugated nanobodies normalized compared to randomly-conjugated nanobodies (Figure 2B). These nanobodybased tracers could be used for high contrast imaging as early as $1 \mathrm{~h}$ post-injection (Kijanka et al., 2016; Debie et al., 
2017). Of note, while not directly compared to their randomlyconjugated analog, affibodies expressing a C-terminal cysteine and conjugated at this position with IRDye800CW also enabled imaging at the expected early timepoints (Sexton et al., 2013; de Souza et al., 2017; Ribeiro de Souza et al., 2018).

With the aim of optimizing the pharmacokinetic profile of tracers, the chemical design of fluorophores can be systematically modified. Variations in the overall charge, total number of charges and hydrophilicity of a Cy5 dye have led to a hybrid cRGD-tracer with improved properties regarding nonspecific background signals, renal elimination, and tumor uptake (Bunschoten et al., 2016). A similar strategy was applied for the optimization of the cRGD peptide as well as a KUE anti-PSMA peptide, with heptamethine fluorophores. However, conclusions of such studies on the most optimal design of fluorophores for peptide conjugation are difficult to generalize as the obtained results are also highly dependent on the physicochemical properties of the peptide itself (Choi et al., 2013; Bao et al., 2017). It is therefore becoming evident, that selection of an appropriate fluorophore and labeling strategy is an essential part of the fluorescent tracer design. For protein-based ligands such as antibodies, antibody-fragments, and scaffold proteins general properties and guidelines concerning the conjugation of certain fluorophores can be established, whereas in small peptides and molecules optimization in the design of new conjugates may be required on an individual basis.

\section{Targets for FIGS With Molecular-Targeted Tracers}

In the current preclinical and clinical FIGS studies, a wide variety of biomarkers have been investigated as potential targets. Extracellular molecules enable targeting with non-cell penetrating ligands, and cell-membrane bound biomarkers are often preferred, as diffusion of secreted targets will reduce the sharpness of imaging. Biomarkers overexpressed by the cancer cells themselves are popular as they are already widely used for targeted therapeutic or nuclear imaging applications (Boonstra et al., 2016). Targets having shown high-level and quite general overexpression within specific cancer types include folate receptor $\alpha(\mathrm{FR} \alpha)$, which is mainly known for ovarian cancer (Kalli et al., 2008), CEA in colorectal and pancreatic cancer (van Oosten et al., 2011; de Geus et al., 2016), and PSMA in prostate cancer (Perner et al., 2007). One of the most highly overexpressed biomarkers is the breast cancer marker human epidermal growth factor 2 (HER2). While high contrast in HER2 overexpressing cells will likely be achieved, the fact that this marker is only overexpressed in a small subset of patients can be problematic in the sense that pre-operative screening would be required (Harbeck and Gnant, 2017). In order to generate more widely applicable FIGS tracers, the search for more general tumor markers is ongoing. Targets such as EGFR, carbonic anhydrase 9 (CAIX) and the epidermal cell adhesion molecule (EpCAM) have been suggested and explored to this end (Boonstra et al., 2015a, 2016).

Another strategy lies in the targeting of the tumor stroma, instead of only the tumor cells. This has several distinct advantages, namely, stroma is present on the tumor periphery/invasive edge and is part of a general physiological process, implying the presence of cancer-type independent markers, such as markers associated with infiltration of angiogenesis, tumor associated immune cells, or fibroblasts (Boonstra et al., 2015a). Examples of potential stromal targets include the soluble, cell-released vascular endothelial growth factor (VEGF-A) as marker for angiogenesis or the fibroblast activation protein alpha (FAP- $\alpha$ ) for fibroblast targeting. Several markers also share stromal and tumor cell expression, and may as such be especially interesting. Examples are uPAR and integrins such as $\alpha_{v} \beta_{3}$ (Boonstra et al., 2015a; Hamidi and Ivaska, 2018). In all cases, constitutive expression in normal or fibrotic tissue could be a limiting factor as it will cause on-target, off-tumor uptake. Moreover, one should always take intra-tumoral heterogeneity into consideration (Pogue et al., 2018).

\section{Targeting Ligands}

As for targeting moieties, a host of possible types of molecules are available. These range from full IgG antibodies, to antibody fragments, scaffold proteins, peptides, and small molecules. A comprehensive overview of the different targeting ligands that have been investigated preclinically and clinically in the context of FIGS is given in Table $\mathbf{1}$.

Antibodies are large $(150 \mathrm{kDa})$ proteins that bivalently attach to their molecular target with high affinity and specificity. The large size of antibodies, as well as the presence of an Fc-domain bestow a long blood half-life and limit tumor penetration. Indeed, as is known from nuclear molecular imaging, the use of antibodies as targeted fluorescent contrast agents for FIGS necessitates extended waiting periods of several days to obtain sufficient target-specific contrast (Freise and $\mathrm{Wu}$, 2015). Antibody-based FIGS tracers represent the largest group of currently evaluated compounds as monoclonal antibodies against a wide variety of targets are readily available and can be straightforwardly repurposed following fluorophore conjugation. For example, the therapeutic EGFR targeting antibodies Cetuximab and Panitumumab, and the anti-VEGFA antibody Bevacizumab have been, after labeling with IRDye800CW, broadly explored in the context of FIGS in a range of pathologies such as head and neck cancer, colorectal cancer, breast cancer, pancreatic cancer, and glioblastoma (Heath et al., 2012; Day et al., 2013a,b; Gong et al., 2014; Korb et al., 2014; De Boer et al., 2015; Warram et al., 2015, 2016; Rosenthal et al., 2016, 2017; Moore et al., 2017; Gao et al., 2018a,b; Prince et al., 2018; Tummers et al., 2018b; van Keulen et al., 2019). Early phase clinical trials demonstrated the feasibility of intraoperative lesion detection and this was confirmed by histological evidence. The anti-CEA compound SGM-101, consisting of the novel antibody SGM-ch511 and the fluorophore BM104 (Figure 1A) (the NHSactivated version of BM104 is called BM105) is currently being evaluated in a phase III clinical trial for colorectal cancer. In addition, the potential of many more NIR-labeled antibodies (most often labeled with IRDye800CW) has been investigated in a variety of subcutaneous, orthotopic, and metastatic mouse models, including the anti-(human) EpCAM antibody 323/A3 (van Driel et al., 2016) or anti-uPAR antibody ATN-658 


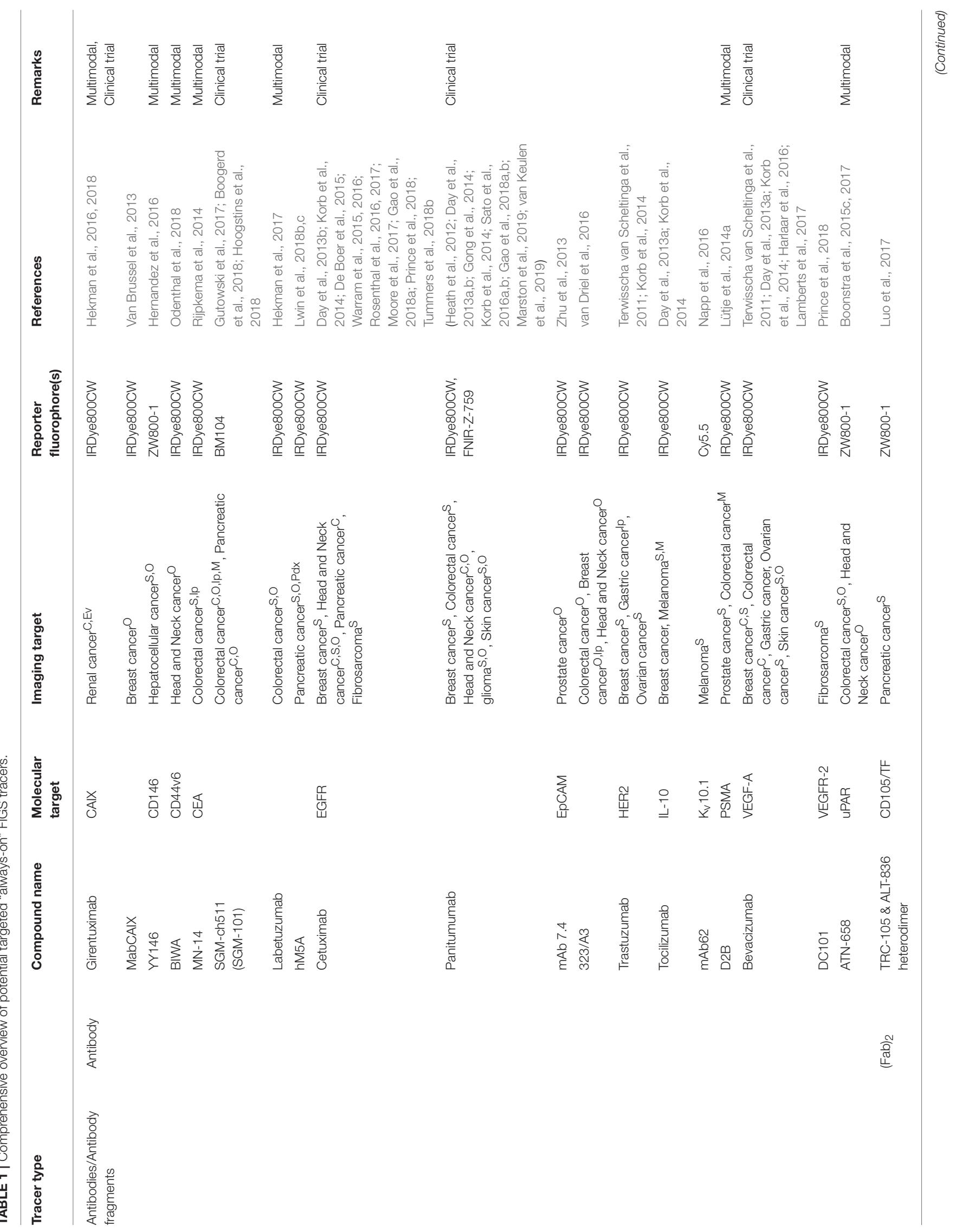




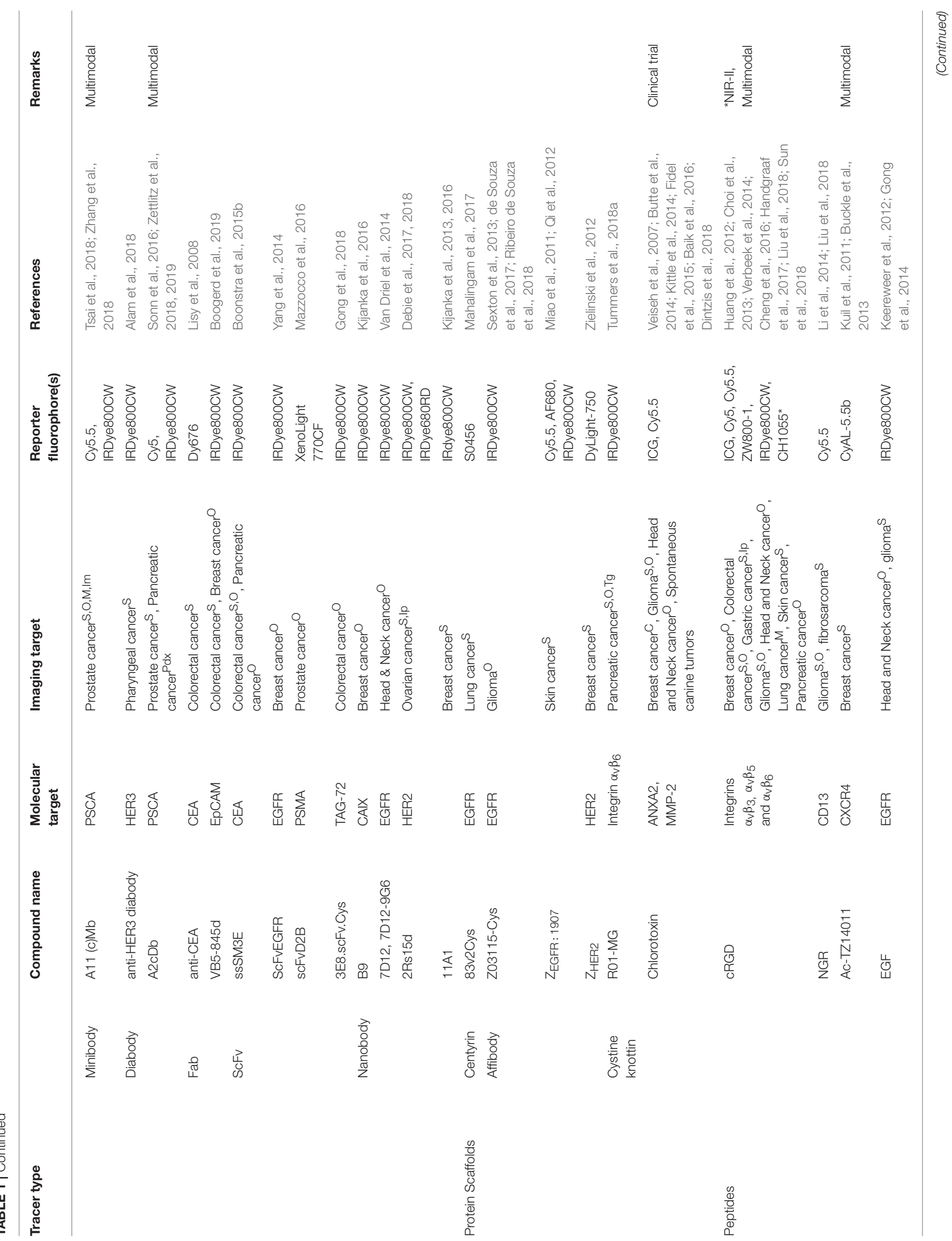




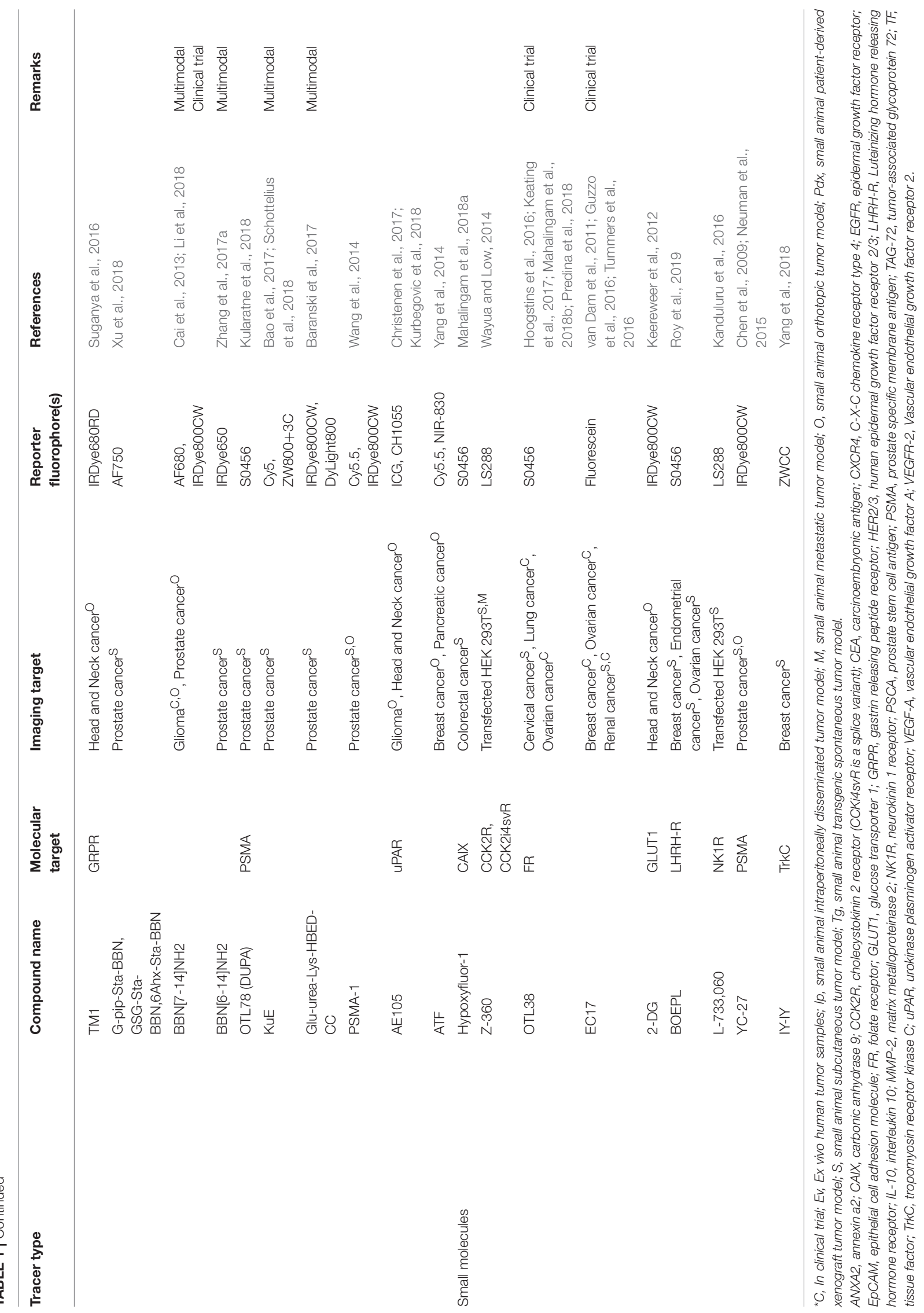


(Boonstra et al., 2017) for colorectal, head and neck, and/or breast cancer.

To achieve more rapid pharmacokinetics, antibody fragments, obtained through protein engineering, can be considered. Minibodies, consisting of two scFv-CH3 chains are, with $80 \mathrm{kDa}$, about half the size of full antibodies. Furthermore, they lack a functional Fc-region, preventing extended circulation due to FcRn recycling. A recent study demonstrated the use of an anti-(human) PSCA minibody, called A11, conjugated with IRDye800CW in different mouse models. Subcutaneous, orthotopic and intramuscular implanted tumors and tumor positive lymph nodes could be clearly visualized, even in knock-in models expressing the human homolog of PSCA (Zhang et al., 2018). Furthermore, fluorescenceguided resection of intramuscular tumors, revealed superior overall survival compared to conventional white light surgery (Zhang et al., 2018).

However, the size of minibodies does still put them above the cut-off value for renal clearance. Compounds smaller than 60 $\mathrm{kDa}$ are generally cleared via the kidneys, resulting in faster blood clearance, and correspondingly, diminished non-specific uptake. High contrast should thus be attained at an earlier timepoint, though at the expense of total tumor uptake (total fluorescent signal) (Freise and $\mathrm{Wu}, 2015)$. It has furthermore been shown that an inverse relation exists between the compound's size and its rate of tissue penetration, meaning that smaller fragments will distribute more quickly and more deeply throughout tumor and healthy tissues (Li et al., 2016; Xenaki et al., 2017). Antibody fragment types that are under investigation for FIGS are scFv's $(25 \mathrm{kDa})$, diabodies ( $\mathrm{scFv}$ dimer, $50 \mathrm{kDa}$ ), and Fab fragments (single scFv-CH3 chain, $55 \mathrm{kDa}$ ). The PSCA-specific diabody $\mathrm{A} 2 \mathrm{cDb}$, site-specifically conjugated to $\mathrm{Cy} 5$ was evaluated in murine subcutaneous and intramuscular prostate cancer models and optimal imaging contrast was achieved within $6 \mathrm{~h}$ postinjection (Sonn et al., 2016). The same diabody, site-specifically conjugated to IRDye800CW and directly labeled with ${ }^{124} \mathrm{I}$, was recently used as bimodal tracer for the visualization of PSCApositive pancreatic patient-derived orthotopic xenografts with PET and NIR fluorescence imaging. High-contrast imaging within $24 \mathrm{~h}$ or less was possible. It was furthermore demonstrated that the clearance pattern of the tracer was not significantly different from the iodinated-only form, indicating that the conjugation strategy used for IRDye800CW labeling did not impact the tracer's biodistribution or clearance (Zettlitz et al., 2018). This is in contrast to other studies with small antibody fragments that, as discussed above, often exhibit TBRs that are sufficiently high only between 24 and $72 \mathrm{~h}$ post-injection, as well as a significant amount of uptake in the liver. This has been found to be the case at least for an anti-HER3 diabody, anti-EpCAMFab fragment, and scFv's targeting CEA, EGFR and the tumorassociated glycoprotein 72 (TAG-72), all randomly labeled with IRDye800CW (Yang et al., 2014; Boonstra et al., 2015b; Alam et al., 2018; Gong et al., 2018; Boogerd et al., 2019).

In addition to the antibody fragments derived from conventional antibodies, the monomeric antigen-binding domains of heavy-chain only antibodies, so called single-domain antibodies or nanobodies, have been investigated for FIGS [recently reviewed in Debie et al. (2019)]. In preclinical studies, it has been shown that site-specifically IRDye800CW conjugated anti-HER2 and anti-CAIX nanobodies could achieve high contrast and specific imaging of tumor lesions within the first hours (1-4 h) after injection in murine breast and ovarian cancer models (Kijanka et al., 2013, 2016; Debie et al., 2017, 2018).

An advantage of antibodies and antibody-based tracers is that they can be generated in high through-put using established immunization strategies, and produced via fermentation in animal, yeast or bacterial cells (Ma and O'Kennedy, 2017). For tracer development, antibodies and antibody fragments represent a platform of compounds with a predominantly constant structure, except for variations in the antigen-binding loops prompting different specificities. This allows the definition of general properties and more versatile protocols for tracer preparation. Another type of platform technology are the nonantibody protein scaffolds that have a fixed backbone and are derived from different naturally occurring proteins. New antigenspecific protein scaffolds are selected from synthetic libraries and further engineered in vitro. As opposed to antibody-derived ligands, these compounds undergo no in vivo affinity maturation steps. Many different types of protein scaffolds have been described, but only affibodies, centyrins, and cystine knottins have been evaluated for FIGS so far.

Affibodies are small proteins of about $7 \mathrm{kDa}$ that have been derived from the B-domain of Staphylococcus aureus protein A. They consist of a three helical structure that can, by mutation of 13 amino acids in the first two helices, bind different molecular targets. The affibody tracer ABY-029, directed toward EGFR and conjugated site-specifically with IRDye800CW via a Cterminal cysteine, is currently undergoing clinical translation for FIGS in glioma, head and neck cancer and soft tissue sarcoma. This tracer was first evaluated in an orthotopic human EGFRexpressing glioma model in rats (Figure 3B). The tracer was found to preferentially accumulate in the tumor, and this from $1 \mathrm{~h}$ post-injection onwards (de Souza et al., 2017). Other studies using fluorescently-labeled affibodies targeting EGFR and HER2 show similar optimal imaging timepoints (Zielinski et al., 2012; Tummers et al., 2018a).

Centyrins are $10 \mathrm{kDa}$ fibronectin type III domains, derived from human tenascin, made up of 7 antiparallel $\beta$-strands. Binding affinity against different targets is generated via mutations in the connecting loops. The human/mouse crossreactive anti-EGFR centyrin $83 \mathrm{v} 2$ labeled with the fluorophore S0456, was preclinically tested in subcutaneous lung cancer xenografts. Imaging could be performed within the first hours after injection and peak fluorescence was reached between 6 and $12 \mathrm{~h}$ pi. (Mahalingam et al., 2017).

Cystine knot peptides $(3-4 \mathrm{kDa})$ are built around a naturally occurring motif, where the peptide forms a type of knot stabilized by three cysteine-bridges around a core of antiparallel $\beta$-strands. Through mutations, the loops that connect the strands can confer specific binding capabilities to the knottin peptide. The knottin peptide Tozuleristide, which consists of the scorpion venom derived ligand chlorotoxin conjugated to ICG, is currently undergoing clinical translation. This probe was able to distinguish tumor from normal tissue in resected 
A

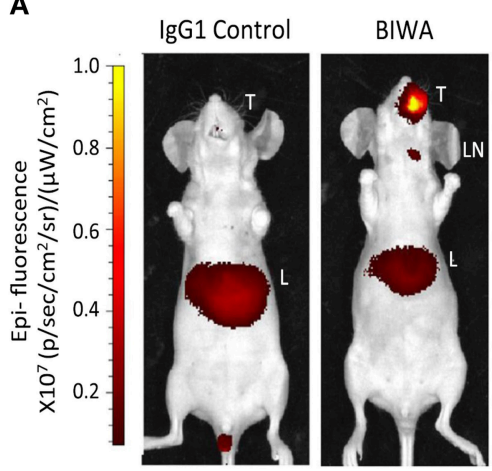

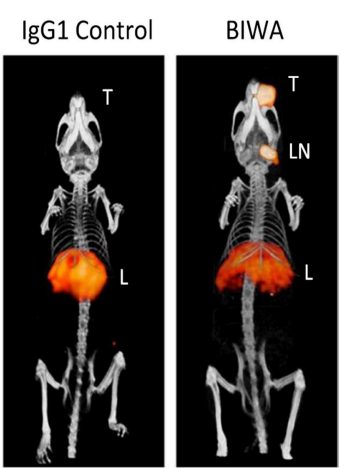

NIR

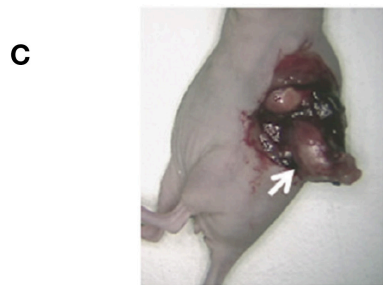

HE

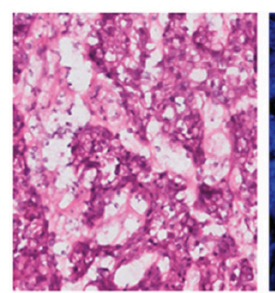

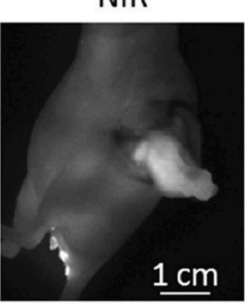

DAPI

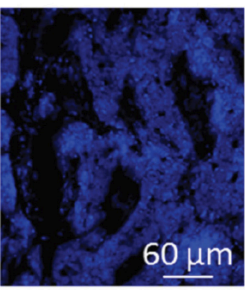

Color-NIR merge

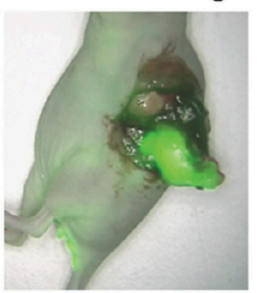

NIR

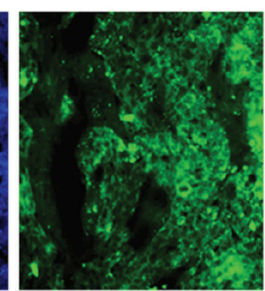

B

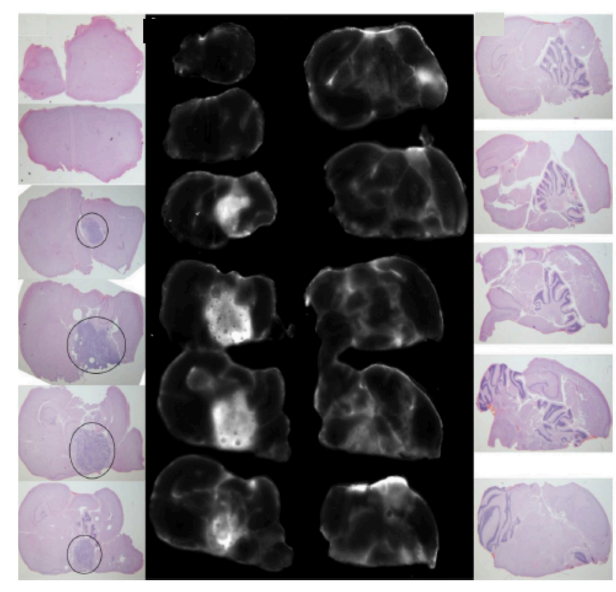

D

Unmixed image

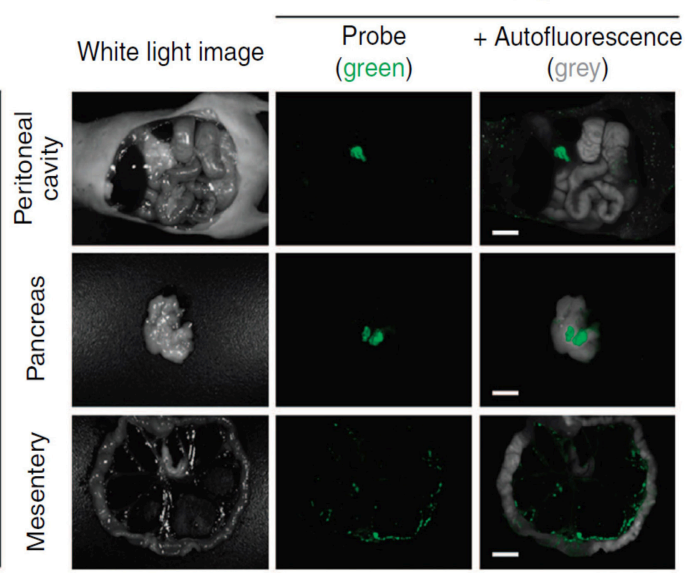

FIGURE 3 | Examples of fluorescence imaging of tumor lesions with various preclinical FIGS tracers. (A) The anti-CD44v6 antibody BIWA co-conjugated with IRDye800CW and ${ }^{111}$ In $72 \mathrm{~h}$ after intravenous (iv) injection in an orthotopic CD44v6+ head and neck tumor model. Fluorescent signals (left) correspond well with results obtained via SPECT/CT imaging (right). Adapted from Odenthal et al. (2018) under the creative commons license. (B) Imaging of orthotopically implanted EGFR+ brain tumor slices after iv administration of an IRDye800CW conjugated anti-EGFR affibody. Tumor on hematoxylin and eosin stained slices co-localizes with high signal intensity on corresponding NIR images. Adapted from de Souza et al. (2017) under the creative commons license. (C) Imaging of an orthotopically implanted pancreatic cancer xenograft $4 \mathrm{~h}$ after iv injection of a ZW800-1 conjugated cRGD peptide. Specific tumor targeting by the tracer is confirmed by hematoxylin and eosin staining. Adapted from Handgraaf et al. (2017) under the creative commons license. (D) Imaging of abdominal ovarian cancer xenograft 5 min after intraperitoneal injection of a HMRef- $\beta$ Gal spirocyclic activatable tracer. Fluorescence becomes activated at the tumor site only. Adapted from Asanuma et al. (2015) under the creative commons license.

human breast cancer specimens between 1 and $26 \mathrm{~h}$ postinjection (Dintzis et al., 2018). Tozuleristide is a naturally occurring knottin, whose exact specificity is not fully known, though MMP-2 and AnnexinA2 have been observed as targets. Alternatively, the knottin peptide R01-MG, with engineered affinity for the human and mouse $\alpha_{v} \beta_{6}$ integrin, has been tested pre-clinically. After conjugation with IRDye800CW, it was evaluated in subcutaneous, orthotopic, and spontaneous tumor models of pancreatic cancer. Fluorescent signal in a subcutaneous tumor became significantly different from a control knottin at $4 \mathrm{~h}$ post-injection, and maximal TBR was reached at $20 \mathrm{~h}$ post-injection. Cancer lesions, including small metastases could be clearly discerned from normal tissue in the orthotopic and spontaneous models (Tummers et al., 2018a).
Other than these scaffold proteins, non-scaffold peptides and small molecules can also be used as tracers in FIGS. The advantage of peptidic and small molecule-based tracers is that they can be produced at reduced cost compared to the other types of tracers. Target specific peptides and small molecules can be generated by rational design, or compounds with pre-existing affinities for the envisaged target, such as natural ligands, can be repurposed as fluorescent tracers. However, their structure and physicochemical properties vary greatly as they do not share a common backbone. General pharmacokinetic characteristics are hard to define, though peptide/small molecule-based tracers are expected to be small enough to attain at least partial renal clearance, depending on their hydrophobicity. 
By far the most investigated peptide, is (cyclic) RGD, which targets a group of integrin receptors through a naturally occurring binding motif. cRGD peptides have been conjugated with a variety of different fluorophores, including Cy5.5, ICG, IRDye800CW and ZW800-1. After evaluation in subcutaneous and orthotopic tumor models of gastric, head and neck, pancreatic (Figure 3C) and colorectal cancer, tumor-tobackground values were generally optimal between 4 and $24 \mathrm{~h}$ post-injection, depending on the fluorophore used (see above) (Choi et al., 2013; Cheng et al., 2016; Handgraaf et al., 2017). Other promising peptides for further development are tracers against for example PSMA (Wang et al., 2014; Bao et al., 2017; Baranski et al., 2017; Kularatne et al., 2018; Schottelius et al., 2018), the gastrin releasing peptide receptor (GRPR) (Cai et al., 2013; Suganya et al., 2016; Zhang et al., 2017a; Li et al., 2018; Xu et al., 2018) and uPAR (Yang et al., 2014; Christenen et al., 2017; Kurbegovic et al., 2018). Folate-receptor specific compounds were the first small molecules to be used in clinical trials for FIGS. The compound EC17 was constructed by conjugating folic acid with fluorescein isothiocyanate (FITC) (wavelength of maximal emission and excitation at $495 / 515 \mathrm{~nm}$, outside the NIR region) (van Dam et al., 2011). EC17 was initially tested during debulking surgery in the case of late stage ovarian cancer, where $\mathrm{FR} \alpha$ is widely expressed. To improve imaging contrast and detection of deeper located lesions, folic acid was labeled instead with the NIR dye S0456, to form OTL38. Additional clinical studies with both tracers have since been performed in lung, ovarian, and renal cancer. The surgical procedure is generally performed between 2 and $6 \mathrm{~h}$ post-injection of either tracer (Hoogstins et al., 2016; Keating et al., 2017; Mahalingam et al., 2018b; Predina et al., 2018).

\section{ACTIVATABLE TRACERS}

An alternative to the conventional "always-on" targeted tracers, is the use of "activatable" or "smart" probes. The general idea behind this approach is that these are non-fluorescent until activation on their target site, thereby suppressing non-specific fluorescence signals and increasing tumorto-background contrast (Lacivita et al., 2012). Two main types of activatable tracers can be distinguished, activatable targeted tracers and enzyme-activated probes (reviewed by Mochida et al., 2018).

Activatable targeted tracers are not dissimilar in structure to always-on tracers, meaning they also consist of a targeting moiety and conjugated fluorophore. The difference lies in the fact that as a result of the presence of a quencher or due to aggregation to the targeting moiety, fluorescence is quenched. Most often, the fluorescent groups only become activated after binding a molecular target on the cell surface, internalization into the targeted cell, and subsequent metabolization. The simplest construction of such a tracer is through the conjugation of ICG to a targeting moiety (Sano et al., 2013; Watanabe et al., 2014). ICG fluorescence has been found to be already significantly quenched at conjugation ratios of 1:1 with a monoclonal antibody. Upon cleavage in the lysosomes, ICG's full fluorescence activity is restored. It is however important to note that hepatic uptake, and consequent clearing of the antibody-ICG conjugate will cause significant background fluorescence (Ogawa et al., 2015). Alternatively, for an ATTO680-Trastuzumab conjugate, the use of a "molecular-switch" has been demonstrated (Kim et al., 2017). In this case, the fluorophore is initially quenched by interaction with tryptophan residues on an antibody's framework, and activated by conformational changes due to receptor binding. The dual labeling of an antibody with a fluorophore and a quencher is another possibility. This was demonstrated in a preclinical study, where the anti-EGFR antibody Cetuximab was co-conjugated with the fluorophore AF660 and quencher IRDye QC-1 at an average antibody:fluorophore:quencher ratio of 1:2:6. Similarly to ICG conjugated compounds, internalization into the target cells and subsequent catabolization will lift the quenching effect and reactivate fluorescence (Obaid et al., 2017).

Enzyme-activated tracers rely on the innate function of a target enzyme to activate the fluorescence of the probe. Proteases such as matrix metalloproteinases (MMPs), cathepsins, and $\beta$ galactosidases are often targeted by these tracers. Activation can occur in several manners. When probes are quenched because of the spatial proximity of the fluorophore to a quenching group (which can also be another fluorophore) cleavage of the tracer will separate the quenching group from the fluorophore and activate the fluorescence. Alternatively, the probe can form a spirocyclic structure caging the fluorophore, and only becoming active when it linearizes after enzymatic cleavage (Lacivita et al., 2012; Mochida et al., 2018). Two enzyme-activated tracers, called LUM015 and AVB-620 are currently being clinically tested. LUM015 is a probe consisting of a quencher, QSY21, linked to a Cy5 fluorophore using the peptide sequence "GGRK," which is in turn also linked to a $20 \mathrm{kDa}$ polyethylene glycol (PEG) on the Cy5 side. Upon cleavage by cathepsins, the Cy5 fluorophore regains its fluorescence. The PEG-chain is included into this structure to slow diffusion of the activated fluorophore and increase contrast. Indeed, if the probe is not retained, diffusion of signal from the cleavage site may negatively impact the potential for tumor delineation. Clinical studies in breast cancer and soft tissue sarcoma patients showed that tumor imaging could be performed between 2 and $30 \mathrm{~h}$ after intravenous injection of this tracer (Whitley et al., 2016; Smith et al., 2018). AVB-620 is an activatable cell-penetrating peptide. It consists of a Cy5 conjugated cell penetrating peptide, bound through a linker to a neutralizing, Cy7 conjugated, sequence. Due to the spatial proximity of both fluorophores, the Cy5 signal is quenched for the Cy7 fluorophore's emission. Upon cleavage by MMP-2 or MMP-9, both sequences are released, leading to cellular uptake of the Cy5 peptide (causing increased retention of fluorescence), increased Cy5 fluorescent signal and decreased Cy7 fluorescence. To differentiate tumor from normal, instead of the total fluorescent signal, the Cy5:Cy7 ratio is determined. In breast cancer patients, tumor delineation was generally possible between 2 and 20 h post-injection (Unkart et al., 2017). Other than these clinical studies, several other enzyme-activated tracers for FIGS are being preclinically developed (Table 2). Besides those that are similarly structured to the clinically investigated compounds (separate fluorophore and quenching group), several 


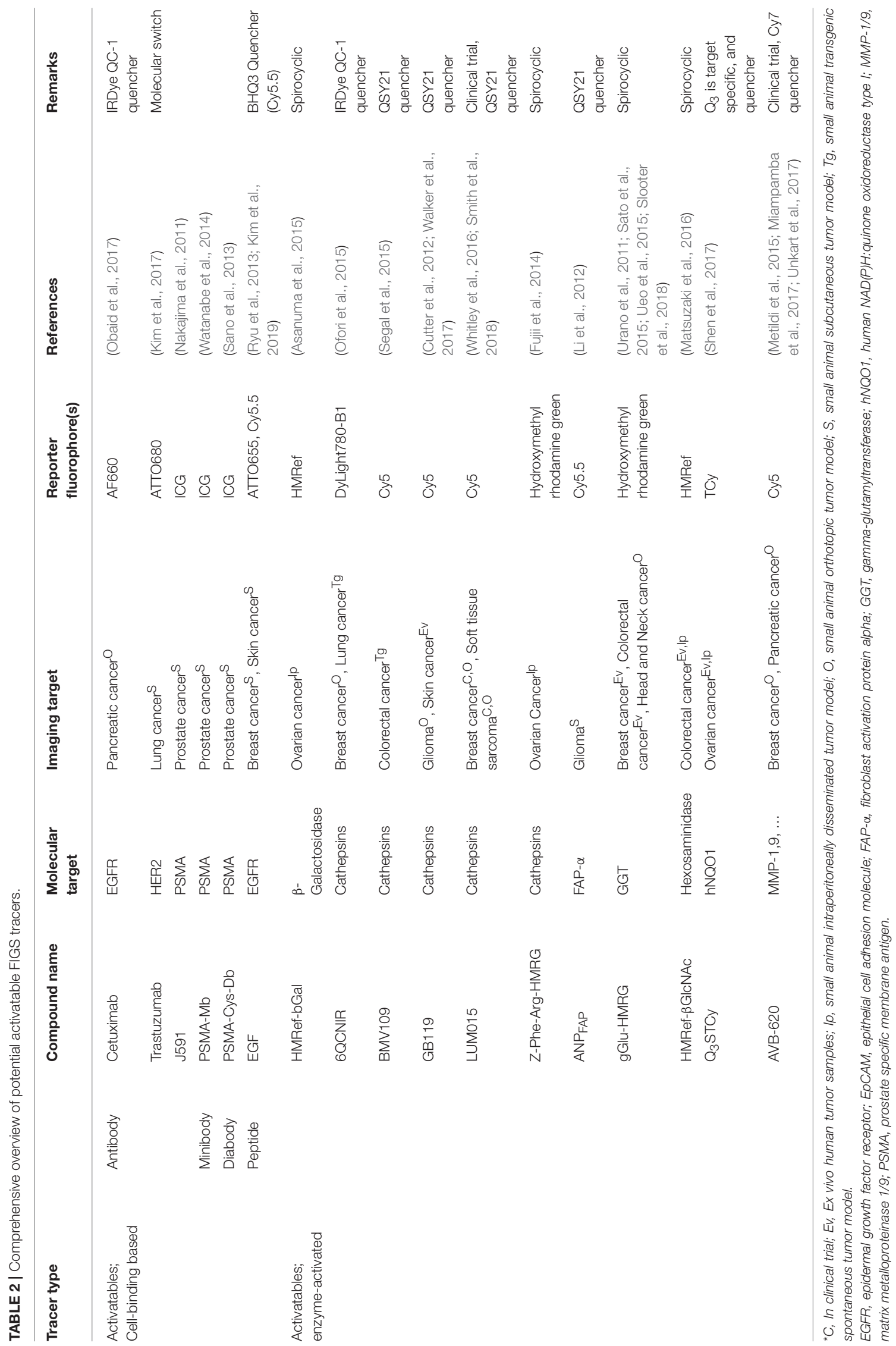


spirocyclic compounds may also be of interest for clinical translation. For example, a $\gamma$-Glutamyl-transpeptidase (GGT) activated probe called gGlu-HMRG was designed using the visible wavelength fluorophore hydroxymethyl rhodamine green (wavelength of maximal excitation/emission at $490 / 520 \mathrm{~nm}$, outside the NIR region). Normally, this tracer is non-fluorescent due to quenching by its spirocyclic structure, but it becomes activated when the enzyme cleaves an internal $\gamma$-glutamyl bond and linearizes (Urano et al., 2011). This tracer, and similarly designed tracers have been tested on excised tumor tissue, and could differentiate tumor from normal after spraying on patient samples of colorectal, breast, oral, and ovarian cancer (Figure 3D) (Urano et al., 2011; Fujii et al., 2014; Asanuma et al., 2015; Sato et al., 2015; Ueo et al., 2015; Matsuzaki et al., 2016; Slooter et al., 2018).

\section{DISCUSSION ON THE FUTURE DEVELOPMENT OF FIGS TRACERS}

Over the last decade, FIGS has been developing at a rising pace and the potential benefits of specific molecular tracers have become clear. Initial successes were reached with the clinical translation of the folate-based tracers EC17 and OTL38 as well as IRDye800CW-labeled antibodies. Meanwhile, additional tracers have entered the phase of clinical evaluation and many more are being tested at preclinical level; from classical antibodybased probes which are widely available and relatively easy to generate, to smaller tracers with higher in vivo specificity and faster kinetics allowing administration shortly before surgery. Novel designs are continuously emerging, and the importance of design-related aspects, such as the physicochemical properties of the fluorophore itself, the type of targeting ligand and the chosen target, have become apparent. Further research is needed to better understand how all these factors impact the in vivo pharmacokinetics and targeting of forthcoming FIGS tracers, to optimize their design and reduce their production cost.

Particular types of molecular tracers may furthermore be more suited for specific applications. For example, hybrid tracers are expected to offer superior sensitivity for the intra-operative detection of metastasized lymph nodes, while the ability to topically apply activatable tracers without the need for washing could be convenient to check the surgical wound for residual disease after resection or for the diagnosis of lesions during endoscopic examination.

\section{REFERENCES}

Alam, M. K., El-Sayed, A., Barreto, K., Bernhard, W., Fonge, H., and Geyer, C. R. (2018). Site-specific fluorescent labeling of antibodies and diabodies using SpyTag/SpyCatcher system for in vivo optical imaging. Mol. Imaging Biol. 21, 54-66. doi: 10.1007/s11307-018-1222-y

Antaris, A. L., Chen, H., Cheng, K., Sun, Y., Hong, G., Qu, C., et al. (2016). A small-molecule dye for NIR-II imaging. Nat. Mater. 15, 235-242. doi: $10.1038 /$ nmat4476

Aoun, F., Albisinni, S., Zanaty, M., Hassan, T., Janetschek, G., and van Velthoven, R. (2017). Indocyanine green fluorescence-guided sentinel lymph
Preclinical studies are valuable for initial assessment of the pharmacokinetics and possible application of FIGS tracers. It is, however, important to also critically appraise conclusions drawn from these studies, as there are limitations to the preclinical models used as indicators of possible future clinical success. Subcutaneous and orthotopic tumor models based on cell lines highly overexpressing the molecular target of interest are suitable for demonstrating specificity of the tracer, by comparing uptake with a non-targeting control compound or in receptor-negative cell line. However, although orthotopic models provide better insight on relevant tissue background signal, the homogenous manner of tumor development in these types of models does not adequately reflect the complexity and heterogeneity of a human tumor including its microenvironment. Furthermore, non-specific uptake of the tracer cannot be properly assessed unless it is reactive for the murine variant of the target as well, or alternatively, unless knock-in models of the relevant target are used. Although patient-derived xenografts can alleviate some of these issues, even using these advanced models, surgical efficiency remains difficult to assess in mice. Large animals may offer improvement as the more sizeable organs and interorgan spaces of i.e., porcine and canine models make for a more realistic setting to assay FIGS contrast agents (Lwin et al., 2018a). Moreover, these can also be used to better estimate the required dose, monitor possible toxic effects, and even identify failure of the hypothesis before unnecessary large cost investments for cGMP drug development are made. In the end, however, the actual clinical value of new tracers can only be established in patients. This will in addition to the determination of merely objective endpoints such as safety, tumor negative margins, recurrence and survival, also enable the evaluation of more subjective outcomes such as quality of life.

\section{AUTHOR CONTRIBUTIONS}

PD and SH composed the manuscript together. Both authors critically revised and approved he manuscript for publication.

\section{FUNDING}

Our research is supported by Stichting tegen Kanker, Fund for Scientific Research Flanders (FWO), Industrial Research Fund (IOF) and Scientific Fund Willy Gepts (WFWG).

node identification in urologic cancers: a systematic review and meta-analysis. Minerva Urol. Nefrol. 70, 361-369. doi: 10.23736/S0393-2249.17.02932-0

Asanuma, D., Sakabe, M., Kamiya, M., Yamamoto, K., Hiratake, J., Ogawa, M., et al. (2015). Sensitive $\beta$-galactosidase-targeting fluorescence probe for visualizing small peritoneal metastatic tumours in vivo. Nat. Commun. 6:6463. doi: $10.1038 /$ ncomms7463

Baik, F. M., Hansen, S., Knoblaugh, S. E., Sahetya, D., Mitchell, R. M., Xu, C., et al. (2016). Fluorescence identification of head and neck squamous cell carcinoma and high-risk oral dysplasia with BLZ-100, a Chlorotoxinindocyanine green conjugate. JAMA Otolaryngol. Head Neck Surg. 142, 330-338. doi: 10.1001/jamaoto.2015.3617 
Bao, K., Lee, J. H., Kang, H., Park, G. K., El Fakhri, G., and Choi, H. S. (2017). PSMA-targeted contrast agents for intraoperative imaging of prostate cancer. Chem. Commun. 53, 1611-1614. doi: 10.1039/C6CC09781B

Baranski, A. C., Schäfer, M., Bauder-Wüst, U., Roscher, M., Schmidt, J., Stenau, E., et al. (2017). PSMA-11 derived dual-labeled PSMA-inhibitors for preoperative PET imaging and precise fluorescence-guided surgery of prostate cancer. $J$. Nucl. Med. 59:201293. doi: 10.2967/jnumed.117.201293

Boogerd, L. S. F., Boonstra, M. C., Prevoo, H. A. J. M., Handgraaf, H. J. M., Kuppen, P. J. K., van de Velde, C. J. H., et al. (2019). Fluorescence-guided tumor detection with a novel anti-EpCAM targeted antibody fragment: preclinical validation. Surg. Oncol. 28, 1-8. doi: 10.1016/j.suronc.2018.10.004

Boogerd, L. S. F., Hoogstins, C. E. S., Schaap, D. P., Kusters, M., Handgraaf, H. J. M., van der Valk, M. J. M., et al. (2018). Safety and effectiveness of SGM-101, a fluorescent antibody targeting carcinoembryonic antigen, for intraoperative detection of colorectal cancer: a dose-escalation pilot study. Lancet Gastroenterol. Hepatol. 3, 181-191. doi: 10.1016/S2468-1253(17)30395-3

Boonstra, M. C., de Geus, S. W., Prevoo, H. A., Hawinkels, L. J., van de Velde, C. J., Kuppen, P. J., et al. (2016). Selecting targets for tumor imaging: an overview of cancer-associated membrane proteins. Biomark. Cancer 8:119. doi: 10.4137/BIC.S38542

Boonstra, M. C., Prakash, J., Van De Velde, C. J., Mesker, W. E., Kuppen, P. J., Vahrmeijer, A. L., et al. (2015a). Stromal targets for fluorescent-guided oncologic surgery. Front. Oncol. 5:254. doi: 10.3389/fonc.2015.00254

Boonstra, M. C., Tolner, B., Schaafsma, B. E., Boogerd, L. S., Prevoo, H. A., Bhavsar, G., et al. (2015b). Preclinical evaluation of a novel CEA-targeting near-infrared fluorescent tracer delineating colorectal and pancreatic tumors. Int. J. Cancer 137, 1910-1920. doi: 10.1002/ijc.29571

Boonstra, M. C., van Driel, P. B., van Willigen, D. M., Stammes, M. A., Prevoo, H. A., Tummers, Q. R., et al. (2015c). uPAR-targeted multimodal tracer for pre- and intraoperative imaging in cancer surgery. Oncotarget 6, 14260-14273. doi: 10.18632/oncotarget.3680

Boonstra, M. C., Van Driel, P. B. A. A., Keereweer, S., Prevoo, H. A. J. M., Stammes, M. A., Baart, V. M., et al. (2017). Preclinical uPAR-targeted multimodal imaging of locoregional oral cancer. Oral. Oncol. 66, 1-8. doi: 10.1016/j.oraloncology.2016.12.026

Buckle, T., Kuil, J., van den Berg, N. S., Bunschoten, A., Lamb, H. J., Yuan, H., et al. (2013). Use of a single hybrid imaging agent for integration of target validation with in vivo and ex vivo imaging of mouse tumor lesions resembling human DCIS. PLoS ONE 8:e48324. doi: 10.1371/journal.pone.0048324

Bunschoten, A., Van Willigen, D. M., Buckle, T., Van Den Berg, N. S., Welling, M. M., Spa, S. J., et al. (2016). Tailoring fluorescent dyes to optimize a hybrid RGDtracer. Bioconjug. Chem. 27, 1253-1258. doi: 10.1021/acs.bioconjchem.6b00093

Butte, P. V., Mamelak, A., Parrish-Novak, J., Drazin, D., Shweikeh, F., Gangalum, P. R., et al. (2014). Near-infrared imaging of brain tumors using the Tumor Paint BLZ-100 to achieve near-complete resection of brain tumors. Neurosurg. Focus 36:E1. doi: 10.3171/2013.11.FOCUS13497

Cai, Q. Y., Yu, P., Besch-Williford, C., Smith, C. J., Sieckman, G. L., Hoffman, T. J., et al. (2013). Near-infrared fluorescence imaging of gastrin releasing peptide receptor targeting in prostate cancer lymph node metastases. Prostate 73, 842-854. doi: $10.1002 /$ pros. 22630

Chand, M., Keller, D. S., Joshi, H. M., Devoto, L., Rodriguez-Justo, M., and Cohen, R. (2018). Feasibility of fluorescence lymph node imaging in colon cancer: FLICC. Tech. Coloproctol. 22, 271-277. doi: 10.1007/s10151-018-1773-6

Chen, Y., Dhara, S., Banerjee, S. R., Byun, Y., Pullambhatla, M., Mease, R. C., et al. (2009). A low molecular weight PSMA-based fluorescent imaging agent for cancer. Biochem. Biophys. Res. Commun. 390, 624-629. doi: 10.1016/j.bbrc.2009.10.017

Cheng, H., Chi, C., Shang, W., Rengaowa, S., Cui, J., Ye, J., et al. (2016). Precise integrin-targeting near-infrared imaging-guided surgical method increases surgical qualification of peritoneal carcino-matosis from gastric cancer in mice. Oncotarget 8, 6258-6272. doi: 10.18632/oncotarget.14058

Choi, H. S., Gibbs, S. L., Lee, J. H., Kim, S. H., Ashitate, Y., Liu, F., et al. (2013). Targeted zwitterionic near-infrared fluorophores for improved optical imaging. Nat. Biotechnol. 31, 148-153. doi: 10.1038/nbt.2468

Choi, H. S., Nasr, K., Alyabyev, S., Feith, D., Lee, J. H., Kim, S. H., et al. (2011). Synthesis and in vivo fate of zwitterionic near-infrared fluorophores. Angew. Chem. Int. Ed. 50, 6258-6263. doi: 10.1002/anie.201102459
Christenen, A., Juhl, K., Persson, M., Charabi, B. W., Mortensen, J., Kiss, K., et al. (2017). uPAR-targeted optical near-infrared (NIR) fluorescence imaging and PET for image-guided surgery in head and neck cancer: proof-of-concept in orthotopic xenograft model. Oncotarget 8, 15407-15419. doi: 10.18632/oncotarget.14282

Cilliers, C., Nessler, I., Christodolu, N., and Thurber, G. M. (2017). Tracking antibody distribution with near-infrared fluorescent dyes: impact of dye structure and degree of labeling on plasma clearance. Mol. Pharm. 14, 1623-1633. doi: 10.1021/acs.molpharmaceut.6b01091

Cutter, J. L., Cohen, N. T., Wang, J., Sloan, A. E., Cohen, A. R., Panneerselvam, A., et al. (2012). Topical application of activity-based probes for visualization of brain tumor tissue. PLoS ONE 7:e33060. doi: 10.1371/journal.pone.0033060

Danhier, F. (2016). To exploit the tumor microenvironment: since the EPR effect fails in the clinic, what is the future of nanomedicine? J. Control. Release 244, 108-121. doi: 10.1016/j.jconrel.2016.11.015

Day, K. E., Beck, L. N., Deep, N. L., Kovar, J., Zinn, K. R., and Rosenthal, E. L. (2013a). Fluorescently labeled therapeutic antibodies for detection of microscopic melanoma. Laryngoscope 123, 2681-2689. doi: 10.1002/lary.24102

Day, K. E., Sweeny, L., Kulbersh, B., Zinn, K. R., and Rosenthal, E. L. (2013b). Preclinical comparison of near-infrared-labeled cetuximab and panitumumab for optical imaging of head and neck squamous cell carcinoma. Mol. Imaging Biol. 15, 722-729. doi: 10.1007/s11307-013-0652-9

De Boer, E., Warram, J. M., Tucker, M. D., Hartman, Y. E., Moore, L. S., De Jong, J. S., et al. (2015). In vivo fluorescence immunohistochemistry: localization of fluorescently labeled cetuximab in squamous cell carcinomas. Sci. Rep. 5:10169. doi: 10.1038/srep10169

de Geus, S. W., Boogerd, L. S., Swijnenburg, R. J., Mieog, J. S., Tummers, W. S., Prevoo, H. A., et al. (2016). Selecting tumor-specific molecular targets in pancreatic adenocarcinoma: paving the way for image-guided pancreatic surgery. Mol. Imaging Biol. 18, 807-819. doi: 10.1007/s11307-016-0959-4

de Souza, A. L., Marra, K., Gunn, J., Samkoe, K. S., Hoopes, P. J., Feldwisch, J., et al. (2017). Fluorescent affibody molecule administered in vivo at a microdose level labels EGFR expressing glioma tumor regions. Mol. Imaging Biol. 19, 41-48. doi: 10.1007/s11307-016-0980-7

Debie, P., Devoogdt, N., and Hernot, S. (2019). Targeted nanobody-based molecular tracers for nuclear imaging and image-guided surgery. Antibodies 8:12. doi: 10.3390/antib8010012

Debie, P., Van Quathem, J., Hansen, I., Bala, G., Massa, S., Devoogdt, N., et al. (2017). Effect of dye and conjugation chemistry on the biodistribution profile of near-infrared-labeled nanobodies as tracers for image-guided surgery. Mol. Pharm. 14, 1145-1153. doi: 10.1021/acs.molpharmaceut.6b01053

Debie, P., Vanhoeij, M., Poortmans, N., Puttemans, J., Gillis, K., Devoogdt, N., et al. (2018). Improved debulking of peritoneal tumor implants by near-infrared fluorescent nanobody image guidance in an experimental mouse model. Mol. Imaging Biol. 20, 361-367. doi: 10.1007/s11307-017-1134-2

Dintzis, S. M., Hansen, S., Harrington, K. M., Tan, L. C., Miller, D. M., Ishak, L., et al. (2018). Real-time visualization of breast carcinoma in pathology specimens from patients receiving fluorescent tumor-marking agent tozuleristide. Arch. Pathol. Lab. Med. doi: 10.5858/arpa.2018-0197-OA. [Epub ahead of print].

El-Sayed, A., Bernhard, W., Barreto, K., Gonzalez, C., Hill, W., Pastushok, L., et al. (2018). Evaluation of antibody fragment properties for near-infrared fluorescence imaging of HER3-positive cancer xenografts. Theranostics 8, 4856-4869. doi: 10.7150/thno.24252

Fidel, J., Kennedy, K. C., Dernell, W. S., Hansen, S., Wiss, V., Stroud, M. R., et al. (2015). Preclinical validation of the utility of BLZ-100 in providing fluorescence contrast for imaging spontaneous solid tumors. Cancer Res. 75, 4283-4291. doi: 10.1158/0008-5472.CAN-15-0471

Freise, A. C., and $\mathrm{Wu}, \mathrm{A} . \mathrm{M}$. (2015). In vivo imaging with antibodies and engineered fragments. Mol. Immunol. 67, 142-152. doi: 10.1016/j.molimm.2015.04.001

Fujii, T., Kamiya, M., and Urano, Y. (2014). In vivo imaging of intraperitoneally disseminated tumors in model mice by using activatable fluorescent smallmolecular probes for activity of cathepsins. Bioconjug. Chem. 25, 1838-1846. doi: 10.1021/bc5003289

Gao, R. W., Teraphongphom, N., de Boer, E., van den Berg, N. S., Divi, V., Kaplan, M. J., et al. (2018a). Safety of panitumumab-IRDye800CW and 
cetuximab-IRDye800CW for fluorescence-guided surgical navigation in head and neck cancers. Theranostics 8, 2488-2495. doi: 10.7150/thno.24487

Gao, R. W., Teraphongphom, N. T., van den Berg, N. S., Martin, B. A., Oberhelman, N. J., Divi, V., et al. (2018b). Determination of tumor margins with surgical specimen mapping using near-infrared fluorescence. Cancer Res. 78, 5144-5154. doi: 10.1158/0008-5472.CAN-18-0878

Gong, H., Kovar, J. L., Cheung, L., Rosenthal, E. L., and Olive, D. M. (2014). A comparative study of affibody, panitumumab, and EGF for near-infrared fluorescence imaging of EGFR- and EGFRvIII-expressing tumors. Cancer Biol. Ther. 15, 185-193. doi: 10.4161/cbt.26719

Gong, L., Ding, H., Long, N. E., Sullivan, B. J., Martin, E. W., Magliery, T. J., et al. (2018). A 3E8.scFv.Cys-IR800 conjugate targeting TAG-72 in an orthotopic colorectal cancer model. Mol. Imaging Biol. 20, 47-54. doi: 10.1007/s11307-017-1096-4

Gutowski, M., Framery, B., Boonstra, M. C., Garambois, V., Quenet, F., Dumas, K., et al. (2017). SGM-101: An innovative near-infrared dye-antibody conjugate that targets CEA for fluorescence-guided surgery. Surg. Oncol. 26, 153-162. doi: 10.1016/j.suronc.2017.03.002

Guzzo, T. J., Jiang, J., Keating, J., DeJesus, E., Judy, R., Nie, S., et al. (2016). Intraoperative molecular diagnostic imaging can identify renal cell carcinoma. J. Urol. 195, 748-755. doi: 10.1016/j.juro.2015.09.093

Hamidi, H., and Ivaska, J. (2018). Every step of the way: integrins in cancer progression and metastasis. Nat. Rev. Cancer 8, 533-548. doi: 10.1038/s41568-018-0038-Z

Handgraaf, H. J. M., Boonstra, M. C., Prevoo, H. A. J. M., Kuil, J., Bordo, M. W., Boogerd, L. S. F., et al. (2017). Real-time near-infrared fluorescence imaging using cRGD-ZW800-1 for intraoperative visualization of multiple cancer types. Oncotarget 8, 21054-21066. doi: 10.18632/oncotarget.15486

Harbeck, N., and Gnant, M. (2017). Breast cancer. Lancet 389, 1134-1150. doi: 10.1016/S0140-6736(16)31891-8

Harlaar, N. J., Koller, M., de Jongh, S. J., van Leeuwen, B. L., Hemmer, P. H., Kruijff, S., et al. (2016). Molecular fluorescence-guided surgery of peritoneal carcinomatosis of colorectal origin: a single-centre feasibility study. Lancet Gastroenterol. Hepatol. 1, 283-290. doi: 10.1016/S2468-1253(16)30082-6

Heath, C. H., Deep, N. L., Sweeny, L., Zinn, K. R., and Rosenthal, E. L. (2012). Use of Panitumumab-IRDye800 to image microscopic head and neck cancer in an orthotopic surgical model. Ann. Surg. Oncol. 19, 3879-3887. doi: 10.1245/s10434-012-2435-y

Hekman, M. C., Rijpkema, M., Muselaers, C. H., Oosterwijk, E., HulsbergenVan de Kaa, C. A., Boerman, O. C., et al. (2018). Tumor-targeted dualmodality imaging to improve intraoperative visualization of clear cell renal cell carcinoma: a first in man study. Theranostics 8, 2161-2170. doi: $10.7150 /$ thno. 23335

Hekman, M. C. H., Boerman, O. C., De Weijert, M., Bos, D. L., Oosterwijk, E., Langenhuijsen, H. F., et al. (2016). Targeted dual-modality imaging in renal cell carcinoma: an ex vivo kidney perfusion study. Clin. Cancer Res. 22, 4634-46442. doi: 10.1158/1078-0432.CCR-15-2937

Hekman, M. C. H., Rijpkema, M., Bos, D. L., Oosterwijk, E., Goldenberg, D. M., Mulders, P. F. A., et al. (2017). Detection of micrometastases using SPECT/fluorescence dual-modality imaging in a CEA-expressing tumor model. J. Nucl. Med. 58:185470. doi: 10.2967/jnumed.116.185470

Hentzen, J. E. K. R., de Jongh, S. J., Hemmer, P. H. J., van der Plas, W. Y., van Dam, G. M., and Kruijff, S. (2018). Molecular fluorescence-guided surgery of peritoneal carcinomatosis of colorectal origin: a narrative review. J. Surg. Oncol. 118, 332-343. doi: 10.1002/jso.25106

Hernandez, R., Sun, H., England, C. G., Valdovinos, H. F., Ehlerding, E. B., Barnhart, T. E., et al. (2016). CD146-targeted immunoPET and NIRF imaging of hepatocellular carcinoma with a dual-labeled monoclonal antibody. Theranostics 6, 1918-1933. doi: 10.7150/thno.15568

Holm, C. (2010). Clinical applications of ICG fluorescence imaging in plastic and reconstructive surgery. Open Surg. Oncol. J. 210, 37-47. doi: 10.2174/1876504101002020037

Hong, G., Antaris, A. L., and Dai, H. (2017). Near-infrared fluorophores for biomedical imaging. Nat. Biomed. Eng. 1:0010. doi: 10.1038/s41 551-016-0010

Hoogstins, C. E., Tummers, Q. R., Gaarenstroom, K. N., de Kroon, C. D., Trimbos, J. B., Bosse, T., et al. (2016). A novel tumor-specific agent for intraoperative near-infrared fluorescence imaging : a translational study in healthy volunteers and patients with ovarian cancer. Clin. Cancer Res. 22, 2929-2938. doi: 10.1158/1078-0432.CCR-15-2640

Hoogstins, C. E. S., Boogerd, L. S. F., Sibinga Mulder, B. G., Mieog, J. S. D., Swijnenburg, R. J., van de Velde, C. J. H., et al. (2018). Image-guided surgery in patients with pancreatic cancer: first results of a clinical trial using SGM-101, a novel carcinoembryonic antigen-targeting, near-infrared fluorescent agent. Ann. Surg. Oncol. 25, 3350-3357. doi: 10.1245/s10434-018-6655-7

Huang, R., Vider, J., Kovar, J. L., Olive, D. M., Mellinghoff, I. K., MayerKuckuk, P., et al. (2012). Integrin $\alpha v \beta 3$-targeted IRDye 800CW near-infrared imaging of glioblastoma. Clin. Cancer Res. 18, 5731-5740. doi: 10.1158/1078-0432.CCR-12-0374

Hyun, H., Owens, E. A., Narayana, L., Wada, H., Gravier, J., Bao, K., et al. (2014). Central C-C bonding increases optical and chemical stability of NIR fluorophores. RSC Adv. 4, 58762-58768. doi: 10.1039/C4RA11225C

Iijima, T., Aoyagi, T., Iwao, Y., Masuda, J., Fuse, M., Kobayashi, N., et al. (1997). Cardiac output and circulating blood volume analysis by pulse dyedensitometry. J Clin Monit. 13, 81-89.

Javidfar, J., Speicher, P. J., Hartwig, M. G., D’Amico, T. A., and Berry, M. F. (2016). Impact of positive margins on survival in patients undergoing esophagogastrectomy for esophageal cancer presented at the poster session of the fifty-first annual meeting of the society of Thoracic Surgeons, San Diego, CA, Jan 24-28, 2015. Ann. Thorac. Surg. 101, 1060-1067. doi: 10.1016/j.athoracsur.2015.09.005

Jin, T. (2019). Critical review-recent progress in NIR fluorophores emitting over $1000 \mathrm{~nm}$ for Bioimaging. ECS J. Solid State Sci. Technol. 8, R9-R13. doi: 10.1149/2.0111901jss

Juhl, K., Christensen, A., Persson, M., Ploug, M., and Kjaer, A. (2016). PeptideBased optical uPAR imaging for surgery: in vivo testing of ICG-Glu-GluAE105. PLoS ONE 11:e0147428. doi: 10.1371/journal.pone.0147428

Kalli, K. R., Oberg, A. L., Keeney, G. L., Christianson, T. J., Low, P. S., Knutson, K. L., et al. (2008). Folate receptor alpha as a tumor target in epithelial ovarian cancer. Gynecol. Oncol. 108, 619-626. doi: 10.1016/j.ygyno.2007.11.020

Kanduluru, A. K., Srinivasarao, M., and Low, P. S. (2016). Design, synthesis, and evaluation of a neurokinin-1 receptor-targeted near-IR dye for fluorescenceguided surgery of neuroendocrine cancers. Bioconjug. Chem. 27, 2157-2165. doi: 10.1021/acs.bioconjchem.6b00374

Keating, J. J., Runge, J. J., Singhal, S., Nims, S., Venegas, O., Durham, A. C., et al. (2017). Intraoperative near-infrared fluorescence imaging targeting folate receptors identifies lung cancer in a large-animal model. Cancer 123, 1051-1060. doi: 10.1002/cncr.30419

Keereweer, S., Kerrebijn, J. D., Mol, I. M., Mieog, J. S., van Driel, P. B., Baatenburg de Jong, R. J., et al. (2012). Optical imaging of oral squamous cell carcinoma and cervical lymph node metastasis. Head Neck 34, 1002-1008. doi: 10.1002/hed.21861

Kijanka, M., Warnders, F. J., El Khattabi, M., Lub-De Hooge, M., Van Dam, G. M., Ntziachristos, V., et al. (2013). Rapid optical imaging of human breast tumour xenografts using anti-HER2 VHHs site-directly conjugated to IRDye 800CW for image-guided surgery. Eur. J. Nucl. Med. Mol. Imaging 40, 1718-1729. doi: 10.1007/s00259-013-2471-2

Kijanka, M. M., van Brussel, A. S., van der Wall, E., Mali, W. P., van Diest, P. J., van Bergen En Henegouwen, P. M., et al. (2016). Optical imaging of preinvasive breast cancer with a combination of VHHs targeting CAIX and HER2 increases contrast and facilitates tumour characterization. EJNMMI Res. 6:14. doi: 10.1186/s13550-016-0166-y

Kim, H., Cho, M. H., Choi, H. S., Lee, B. I., and Choi, Y. (2019). Zwitterionic near-infrared fluorophore-conjugated epidermal growth factor for fast, realtime, and target-cell-specific cancer imaging. Theranostics 9, 1085-1095. doi: 10.7150/thno.29719

Kim, H., Choi, H. S., Kim, S. K., Lee, B., and Choi, Y. (2017). Antigenresponsive molecular sensor enables real-time tumor-specific imaging. Theranostics 7, 952-961. doi: 10.7150/thno.16647

Kittle, D. S., Mamelak, M. D. A., Parrish-Novak, J. E., Hansen, S., Patil, R., Gangalum, P. R., et al. (2014). Fluorescence-guided tumor visualization using the tumor paint BLZ-100. Cureus 6:e210. doi: 10.7759/cureus.210

Kobayashi, H., Choyke, P. L., and Ogawa, M. (2016). Monoclonal antibodybased optical molecular imaging probes; considerations and caveats in chemistry, biology and pharmacology. Curr. Opin. Chem. Biol. 33, 32-38. doi: 10.1016/j.cbpa.2016.05.015 
Korb, M. L., Hartman, Y. E., Kovar, J., Zinn, K. R., Bland, K. I., and Rosenthal, E. L. (2014). Use of monoclonal antibody-IRDye800CW bioconjugates in the resection of breast cancer. J. Surg. Res. 188, 119-128. doi: $10.1016 /$ j.jss.2013.11.1089

Korb, M. L., Huh, W. K., Boone, J. D., Warram, J. M., Chung, T. K., de Boer, E., et al. (2015). Laparoscopic fluorescent visualization of the ureter with intravenous IRDye800CW. J. Minim. Invasive Gynecol. 22, 799-806. doi: 10.1016/j.jmig.2015.03.008

Kovar, J. L., Simpson, M. A., Schutz-Geschwender, A., and Olive, D. M. (2007). A systematic approach to the development of fluorescent contrast agents for optical imaging of mouse cancer models. Anal. Biochem. 367, 1-12. doi: 10.1016/j.ab.2007.04.011

Kuil, J., Buckle, T., Yuan, H., van den Berg, N. S., Oishi, S., Fujii, N., et al. (2011). Synthesis and in vitro evaluation of a bimodal CXCR4 antagonistic peptide. Bioconjug. Chem. 22, 859-864. doi: 10.1021/bc2000947

Kularatne, S. A., Thomas, M., Myers, C. H., Gagare, P., Kanduluru, A. K., Crain, C. J., et al. (2018). Evaluation of novel prostate-specific membrane antigen-targeted near-infrared imaging agent for fluorescenceguided surgery for prostate cancer. Clin. Cancer Res. Clincanres. 2018:0803. doi: 10.1158/1078-0432.CCR-18-0803

Kurbegovic, S., Juhl, K., Chen, H., Qu, C., Ding, B., Leth, J. M., et al. (2018). Molecular targeted NIR-II probe for image-guided brain tumor surgery. Bioconjug. Chem. 29, 3833-3840. doi: 10.1021/acs.bioconjchem.8b00669

Lacivita, E., Leopoldo, M., Berardi, F., Colabufo, N. A., and Perrone, R. (2012). Activatable fluorescent probes: a new concept in optical molecular imaging. Curr. Med. Chem. 19, 4731-4741. doi: 10.2174/092986712803341511

Lamberts, L. E., Koch, M., de Jong, J. S., Adams, A. L. L., Glatz, J., Kranendonk, M. E. G., et al. (2017). Tumor-specific uptake of fluorescent bevacizumab-IRDye800CW microdosing in patients with primary breast cancer: a phase I feasibility study. Clin. Cancer Res. 23, 2730-2742. doi: 10.1158/1078-0432.CCR-16-0437

Li, D., Zhang, J., Chi, C., Xiao, X., Wang, J., Lang, L., et al. (2018). Firstin-human study of PET and optical dual-modality image-guided surgery in glioblastoma using Ga-IRDye800CW-BBN. Theranostics 8, 2508-2520. doi: 10.7150/thno.25599

Li, G., Xing, Y., Wang, J., Conti, P. S., and Chen, K. (2014). Nearinfrared fluorescence imaging of $\mathrm{CD} 13$ receptor expression using a novel Cy5.5-labeled dimeric NGR peptide. Amino Acids 46, 1547-1556. doi: $10.1007 / \mathrm{s} 00726-014-1727-\mathrm{x}$

Li, J., Chen, K., Liu, H., Cheng, K., Yang, M., Zhang, J., et al. (2012). Activatable near-infrared fluorescent probe for in vivo imaging of fibroblast activation protein-alpha. Bioconjug. Chem. 23, 1704-1711. doi: 10.1021/bc300278r

Li, Z., Krippendorff, B. F., Sharma, S., Walz, A. C., Lavé, T., and Shah, D. K. (2016). Influence of molecular size on tissue distribution of antibody fragments. MAbs 8, 113-119. doi: 10.1080/19420862.2015.1111497

Liberale, G., Bourgeois, P., Larsimont, D., Moreau, M., Donckier, V., and Ishizawa, T. (2017). Indocyanine green fluorescence-guided surgery after IV injection in metastatic colorectal cancer: a systematic review. Eur. J. Surg. Oncol. 43, 1656-1667. doi: 10.1016/j.ejso.2017.04.015

Lisy, M. R., Goermar, A., Thomas, C., Pauli, J., Resch-Genger, U., Kaiser, W. A., et al. (2008). In vivo near-infrared fluorescence imaging of carcinoembryonic antigen- expressing tumor cells in mice. Radiology 247, 779-787. doi: 10.1148/radiol.2472070123

Liu, Y., Wang, Z., Li, X., Ma, X., Wang, S., Kang, F., et al. (2018). Near-infrared fluorescent peptides with high tumor selectivity : novel probes for imageguided surgical resection of orthotopic glioma. Mol. Pharm. 16, 108-117. doi: 10.1021/acs.molpharmaceut.8b00888

Luo, H., England, C. G., Goel, S., Graves, S. A., Ai, F., Liu, B., et al. (2017). ImmunoPET and near-infrared fluorescence imaging of pancreatic cancer with a dual-labeled bispecific antibody fragment. Mol. Pharm. 14, 1646-1655. doi: 10.1021/acs.molpharmaceut.6b01123

Lütje, S., Rijpkema, M., Franssen, G. M., Fracasso, G., Helfrich, W., Eek, A., et al. (2014a). Dual-modality image-guided surgery of prostate cancer with a radiolabeled fluorescent anti-PSMA monoclonal antibody. J. Nucl. Med. 55, 995-1001. doi: 10.2967/jnumed.114.138180

Lütje, S., Rijpkema, M., Helfrich, W., Oyen, W. J., and Boerman, O. C. (2014b). Targeted radionuclide and fluorescence dual-modality imaging of cancer: preclinical advances and clinical translation. Mol. Imaging Biol. 16, 747-755. doi: $10.1007 /$ s11307-014-0747-y

Lwin, T. M., Hoffman, R. M., and Bouvet, M. (2018a). Advantages of patient-derived orthotopic mouse models and genetic reporters for developing fluorescence-guided surgery. J. Surg. Oncol. 118, 253-264. doi: $10.1002 /$ jso. 25150

Lwin, T. M., Miyake, K., Murakami, T., DeLong, J. C., Amirfakhri, S., Filemoni, F., et al. (2018b). Fluorescent humanized anti-CEA antibody specifically labels metastatic pancreatic cancer in a patient-derived orthotopic xenograft (PDOX) mouse model. Oncotarget 9, 37333-37342. doi: 10.18632/oncotarget.26484

Lwin, T. M., Murakami, T., Miyake, K., Yazaki, P. J., Shivley, J. E., Hoffman, R. M., et al. (2018c). Tumor-specific labeling of pancreatic cancer using a humanized anti-CEA antibody conjugated to a near-infrared fluorophore. Ann. Surg. Oncol. 25, 1079-1085. doi: 10.1245/s10434-018-6344-6

Ma, H., and O'Kennedy, R. (2017). Recombinant antibody fragment production. Methods 116, 23-33. doi: 10.1016/j.ymeth.2016.11.008

Mahalingam, S. M., Chu, H., Liu, X., Leamon, C. P., and Low, P. S. (2018a). Carbonic anhydrase IX-targeted near-infrared dye for fluorescence imaging of hypoxic tumors. Bioconjug. Chem. 29, 3320-3331. doi: 10.1021/acs.bioconjchem.8b00509

Mahalingam, S. M., Dudkin, V. Y., Goldberg, S., Klein, D., Yi, F., Singhal, S., et al. (2017). Evaluation of a centyrin-based near-infrared probe for fluorescenceguided surgery of epidermal growth factor receptor positive tumors. Bioconjug. Chem. 28, 2865-2873. doi: 10.1021/acs.bioconjchem.7b00566

Mahalingam, S. M., Kularatne, S. A., Myers, C. H., Gagare, P., Norshi, M., Liu, X., et al. (2018b). Evaluation of novel tumor-targeted near-infrared probe for fluorescence-guided surgery of cancer. J. Med. Chem. 61, 9637-9646. doi: 10.1021/acs.jmedchem.8b01115

Marshall, M. V., Draney, D., Sevick-Muraca, E. M., and Olive, D. M. (2010). Singledose intravenous toxicity study of IRDye $800 \mathrm{CW}$ in sprague-dawley Rats. Mol. Imaging Biol. 12, 583-594. doi: 10.1007/s11307-010-0317-x

Marston, J. C., Kennedy, G. D., Lapi, S. E., Hartman, Y. E., Richardson, M. T., Modi, H. M., et al. (2019). Panitumumab-IRDye800CW for fluorescenceguided surgical resection of colorectal cancer. J. Surg. Res. 239, 44-51. doi: 10.1016/j.jss.2019.01.065

Massa, S., Vikani, N., Betti, C., Ballet, S., Vanderhaegen, S., Steyaert, J., et al. (2016a). Sortase a-mediated site-specific labeling of camelid single-domain antibody-fragments: a versatile strategy for multiple molecular imaging modalities. Contrast. Media Mol. Imaging 11, 328-339. doi: 10.1002/cmmi.1696

Massa, S., Xavier, C., De Vos, J., Caveliers, V., Lahoutte, T., Muyldermans, S., et al. (2014). Site-specific labeling of cysteine-tagged camelid singledomain antibody-fragments for use in molecular imaging. Bioconjug. Chem. 25, 979-988. doi: 10.1021/bc500111t

Massa, S., Xavier, C., Muyldermans, S., and Devoogdt, N. (2016b). Emerging sitespecific bioconjugation strategies for radioimmunotracer development. Exp. Opin. Drug Deliv. 13, 1149-1163. doi: 10.1080/17425247.2016.1178235

Matsuzaki, H., Kamiya, M., Iwatate, R. J., Asanuma, D., Watanabe, T., and Urano, Y. (2016). Novel hexosaminidase-targeting fluorescence probe for visualizing human colorectal cancer. Bioconjug. Chem. 27, 973-981. doi: 10.1021/acs.bioconjchem.6b00037

Mazzocco, C., Fracasso, G., Germain-Genevois, C., Dugot-Senant, N., Figini, M., Colombatti, M., et al. (2016). In vivo imaging of prostate cancer using an anti-PSMA scFv fragment as a probe. Sci. Rep. 6, 10919-10930. doi: $10.1038 /$ srep23314

Metildi, C. A., Felsen, C. N., Savariar, E. N., Nguyen, Q. T., Kaushal, S., Hoffman, R. M., et al. (2015). Ratiometric activatable cell-penetrating peptides label pancreatic cancer, enabling fluorescence-guided surgery, which reduces metastases and recurrence in orthotopic mouse models. Ann. Surg. Oncol. 22, 2082-2087. doi: 10.1245/s10434-014-4144-1

Miampamba, M., Liu, J., Harootunian, A., Gale, A. J., Baird, S., Chen, S. L., et al. (2017). Sensitive in vivo visualization of breast cancer using ratiometric protease-activatable fluorescent imaging agent, AVB-620. Theranostics 7, 3369-3386. doi: 10.7150/thno.20678

Miao, Z., Ren, G., Liu, H., Jiang, L., and Cheng, Z. (2011). Cy5.5labeled affibody molecule for near-infrared fluorescent optical imaging of epidermal growth factor receptor positive tumors. J. Biomed. Opt. 15:036007. doi: $10.1117 / 1.3432738$ 
Mochida, A., Ogata, F., Nagaya, T., Choyke, P. L., and Kobayashi, H. (2018). Activatable fluorescent probes in fluorescence-guided surgery: Practical considerations. Bioorganic Med. Chem. 26, 925-930. doi: 10.1016/j.bmc.2017.12.002

Moore, L. S., Rosenthal, E. L., de Boer, E., Prince, A. C., Patel, N., Richman, J. M., et al. (2017). Effects of an unlabeled loading dose on tumor-specific uptake of a fluorescently labeled antibody for optical surgical navigation. Mol. Imaging Biol. 19, 610-616. doi: 10.1007/s11307-016-1022-1

Mujumdar, R. B., Ernst, L. A., Mujumdar, S. R., Lewis, C. J., and Waggoner, A. S. (1993). Cyanine dye labeling reagents: sulfoindocyanine succinimidyl esters. Bioconjug. Chem. 4, 105-111. doi: 10.1021/bc00020a001

Nagaya, T., Nakamura, Y. A., Choyke, P. L., and Kobayashi, H. (2017). Fluorescence-guided surgery. Front. Oncol. 7:314. doi: $10.3389 /$ fonc. 2017.00314

Nakajima, T., Mitsunaga, M., Bander, N. H., Heston, W. D., Choyke, P. L., and Kobayashi, H. (2011). Targeted, activatable, in vivo fluorescence imaging of Prostate-Specific Membrane Antigen (PSMA) positive tumors using the quenched humanized J591 antibody-indocyanine green (ICG) conjugate. Bioconjug. Chem. 22, 1700-1705. doi: 10.1021/bc2002715

Nakaseko, Y., Ishizawa, T., and Saiura, A. (2018). Fluorescence-guided surgery for liver tumors. J. Surg. Oncol. 2018:324-331. doi: 10.1002/jso.25128

Napp, J., Pardo, L. A., Hartung, F., Tietze, L. F., Stühmer, W., and Alves, F. (2016). In vivo imaging of tumour xenografts with an antibody targeting the potassium channel Kv10.1. Eur. Biophys. J. 45, 721-733. doi: 10.1007/s00249-016-1152-z

Neuman, B. P., Eifler, J. B., Castanares, M., Chowdhury, W. H., Chen, Y., Mease, R. C., et al. (2015). Real-time, near-infrared fluorescence imaging with an optimized dye/light source/camera combination for surgical guidance of prostate cancer. Clin. Cancer Res. 21, 771-780. doi: 10.1158/1078-0432.CCR-14-0891

Nichols, J. W., and Bae, Y. H. (2014). EPR: evidence and fallacy. J. Control. Release 190, 451-464. doi: 10.1016/j.jconrel.2014.03.057

Obaid, G., Spring, B. Q., Bano, S., and Hasan, T. (2017). Activatable clinical fluorophore-quencher antibody pairs as dual molecular probes for the enhanced specificity of image-guided surgery. J. Biomed. Opt. 22:121607. doi: 10.1117/1.JBO.22.12.121607

Odenthal, J., Rijpkema, M., Bos, D., Wagena, E., Croes, H., Grenman, R., et al. (2018). Targeting CD44v6 for fluorescence-guided surgery in head and neck squamous cell carcinoma. Sci. Rep. 8: 10467. doi: 10.1038/s41598-018-28059-9

Ofori, L. O., Withana, N. P., Prestwood, T. R., Verdoes, M., Brady, J. J., Winslow, M. M., et al. (2015). Design of protease activated optical contrast agents that exploit a latent lysosomotropic effect for use in fluorescence-guided surgery. ACS Chem. Biol. 10, 1977-1988. doi: 10.1021/acschembio.5b00205

Ogawa, M., Kosaka, N., Choyke, P. L., and Kobayashi, H. (2009). H-type dimer formation of fluorophores: a mechanism for activatable, in vivo optical molecular imaging. ACS Chem. Biol. 4, 535-546. doi: 10.1021/cb900089j

Ogawa, M., Kosaka, N., Choyke, P. L., and Kobayashi, H. (2015). In vivo molecular imaging of cancer with a quenching near infrared fluorescent probe using conjugates of monoclonal antibodies and indocyanine green. Cancer Res. 69, 1268-1272. doi: 10.1158/0008-5472.CAN-08-3116

Olafsen, T., Cheung, C. W., Yazaki, P. J., Li, L., Sundaresan, G., Gambhir, S. S., et al. (2004). Covalent disulfide-linked anti-CEA diabody allows site-specific conjugation and radiolabeling for tumor targeting applications. Protein Eng. Des. Sel. 17, 21-27. doi: 10.1093/protein/gzh009

Orosco, R. K., Tapia, V. J., Califano, J. A., Clary, B., Cohen, E. E. W., Kane, C., et al. (2018). Positive surgical margins in the 10 most common solid cancers. Sci. Rep. 8:5686. doi: 10.1038/s41598-018-23403-5

Perner, S., Hofer, M. D., Kim, R., Shah, R. B., Li, H., Möller, P., et al. (2007). Prostate-specific membrane antigen expression as a predictor of prostate cancer progression. Hum. Pathol. 38, 696-701. doi: 10.1016/j.humpath.2006.11.012

Pogue, B. W., Rosenthal, E. L., Achilefu, S., and van Dam, G. M. (2018). Perspective review of what is needed for molecular-specific fluorescence-guided surgery. J. Biomed. Opt. 23:1-9. doi: 10.1117/1.JBO.23.10.100601

Predina, J. D., Newton, A. D., Xia, L., Corbett, C., Connolly, C., Shin, M., et al. (2018). An open label trial of folate receptor-targeted intraoperative molecular imaging to localize pulmonary squamous cell carcinomas. Oncotarget 9, 13517-13529. doi: 10.18632/oncotarget.24399

Prince, A. C., McGee, A. S., Siegel, H., Rosenthal, E. L., Behnke, N. K., and Warram, J. M. (2018). Evaluation of fluorescence-guided surgery agents in a murine model of soft tissue fibrosarcoma. J. Surg. Oncol. 117, 1179-1187. doi: $10.1002 /$ jso. 24950

Qi, S., Miao, Z., Liu, H., Xu, Y., Feng, Y., and Cheng, Z. (2012). Evaluation of four affibody-based near-infrared fluorescent probes for optical imaging of epidermal growth factor receptor positive tumors. Bioconjug. Chem. 23, 1149-1156. doi: 10.1021/bc200596a

Ribeiro de Souza, A. L., Marra, K., Gunn, J., Samkoe, K. S., Hull, S., Paulsen, K. D., et al. (2018). Optimizing glioma detection using an EGFR-targeted fluorescent affibody. Photochem. Photobiol. 94, 1167-1171. doi: 10.1111/php.13003

Rijpkema, M., Oyen, W. J., Bos, D., Franssen, G. M., Goldenberg, D. M., and Boerman, O. C. (2014). SPECT- and fluorescence image-guided surgery using a dual-labeled carcinoembryonic antigen-targeting antibody. J. Nucl. Med. 55, 1519-1524. doi: 10.2967/jnumed.114.142141

Rosenthal, E. L., Moore, L. S., Tipirneni, K., De Boer, E., Stevens, T. M., Hartman, Y. E., et al. (2017). Sensitivity and specificity of cetuximab-IRDye800CW to identify regional metastatic disease in head and neck cancer. Clin. Cancer Res. 23, 4744-4752. doi: 10.1158/1078-0432.CCR-16-2968

Rosenthal, E. L., Warram, J. M., de Boer, E., Chung, T. K., Korb, M. L., BrandweinGensler, M., et al. (2016). Safety and tumor-specificity of cetuximab-IRDye 800 for surgical navigation in head and neck cancer. Clin. Cancer Res. 21, 4062-4072. doi: 10.1158/1078-0432.CCR-14-3284

Roy, J., Kaake, M., and Low, P. S. (2019). Small molecule targeted NIR dye conjugate for imaging LHRH receptor positive cancers. Oncotarget 10, 152-160. doi: 10.18632/oncotarget.26520

Ryu, J. H., Shin, M., Kim, S. A., Lee, S., Kim, H., Koo, H., et al. (2013). In vivo fluorescence imaging for cancer diagnosis using receptor-targeted epidermal growth factor-based nanoprobe. Biomaterials 34, 9149-9159. doi: 10.1016/j.biomaterials.2013.08.026

Sano, K., Nakajima, T., Ali, T., Bartlett, D. W., Wu, A. M., Kim, I., et al. (2013). Activatable fluorescent cys-diabody conjugated with indocyanine green derivative: consideration of fluorescent catabolite kinetics on molecular imaging. J. Biomed. Opt. 18:101304. doi: 10.1117/1.JBO.18.10.101304

Sato, C., Abe, S., Saito, Y., So Tsuruki, E., Takamaru, H., Makazu, M., et al. (2015). A pilot study of fluorescent imaging of colorectal tumors using a $\gamma$-glutamyl-transpeptidase-activatable fluorescent probe. Digestion 91, 70-76. doi: $10.1159 / 000369367$

Sato, K., Gorka, A. P., Nagaya, T., Michie, M. S., Nakamura, Y., Nani, R. R., et al. (2016a). Effect of charge localization on the in vivo optical imaging properties of near-infrared cyanine dye/monoclonal antibody conjugates. Mol. Biosyst. 12, 3046-3056. doi: 10.1039/C6MB00371K

Sato, K., Gorka, A. P., Nagaya, T., Michie, M. S., Nani, R. R., Nakamura, Y., et al. (2016b). Role of fluorophore charge on the in vivo optical imaging properties of near-infrared cyanine dye/monoclonal antibody conjugates. Bioconjug. Chem. 27, 404-413. doi: 10.1021/acs.bioconjchem.5b00492

Schottelius, M., Wurzer, A., Wissmiller, K., Beck, R., Koch, M., Gkorpas, D., et al. (2018). Synthesis and preclinical characterization of the PSMA-targeted hybrid tracer PSMA-I\&F for nuclear and fluorescence imaging of prostate cancer. J. Nucl. Med. 60, 71-78. doi: 10.2967/jnumed.118.212720

Segal, E., Prestwood, T. R., Van Der Linden, W. A., Carmi, Y., Bhattacharya, N., Withana, N., et al. (2015). Detection of intestinal cancer by local, Topical application of a quenched fluorescence probe for cysteine cathepsins. Chem. Biol. 22, 148-154. doi: 10.1016/j.chembiol.2014.11.008

Sexton, K., Tichauer, K., Samkoe, K. S., Gunn, J., Hoopes, P. J., and Pogue, B. W. (2013). Fluorescent affibody peptide penetration in glioma margin is superior to full antibody. PLOS ONE 8:e60390. doi: 10.1371/journal. pone.0060390

Shen, Z., Prasai, B., Nakamura, Y., Kobayashi, H., Jackson, M. S., and McCarley, R. L. (2017). A near-infrared, wavelength-shiftable, turn-on fluorescent probe for the detection and imaging of cancer tumor cells. ACS Chem. Biol. 12, 1121-1132. doi: 10.1021/acschembio.6b01094

Siddighi, S., Yune, J. J., and Hardesty, J. (2014). Indocyanine green for intraoperative localization of ureter. Am. J. Obstet. Gynecol. 211:e2. doi: 10.1016/j.ajog.2014.05.017

Slooter, M. D., Handgraaf, H. J. M., Boonstra, M. C., van der Velden, L. A., Bhairosingh, S. S., Que, I., et al. (2018). Detecting tumour-positive resection margins after oral cancer surgery by spraying a fluorescent tracer activated by gamma-glutamyltranspeptidase. Oral Oncol. 78, 1-7. doi: 10.1016/j.oraloncology.2017.12.006 
Smith, B. L., Gadd, M. A., Lanahan, C. R., Rai, U., Tang, R., Rice-Stitt, T., et al. (2018). Real-time, intraoperative detection of residual breast cancer in lumpectomy cavity walls using a novel cathepsin-activated fluorescent imaging system. Breast Cancer Res. Treat. 171, 413-420. doi: 10.1007/s10549-018-4845-4 Sonn, G. A., Behesnilian, A. S., Jiang, Z. K., Zettlitz, K. A., Lepin, E. J., Bentolila, L. A., et al. (2016). Fluorescent image-guided surgery with an anti-Prostate Stem Cell Antigen (PSCA) diabody enables targeted resection of mouse prostate cancer xenografts in real time. Clin. Cancer Res. 22, 1403-1412. doi: 10.1158/1078-0432.CCR-15-0503

Soons, P. A., De Boer, A., Cohen, A. F., and Breimer, D. D. (1991). Assessment of hepatic blood flow in healthy subjects by continuous infusion of indocyanine green. Br. J. Clin. Pharmacol. 32, 697-704.

Stanga, P. E., Lim, J. I., and Hamilton, P. (2003). Indocyanine green angiography in chorioretinal diseases: indications and interpretation: an evidence-based update. Ophtha 110, 13-15. doi: 10.1016/S0161-6420(02)01563-4

Suganya, S. A. A., Kochurani, K. J., Nair, M. G., Louis, J. M., Sankaran, S., Rajagopal, R., et al. (2016). TM1-IR680 peptide for assessment of surgical margin and lymph node metastasis in murine orthotopic model of oral cancer. Sci. Rep. 6:36726. doi: 10.1038/srep36726

Sun, M. M., Beam, K. S., Cerveny, C. G., Hamblett, K. J., Blackmore, R. S., Torgov, M. Y., et al. (2005). Reduction-alkylation strategies for the modification of specific monoclonal antibody bisulfides. Bioconjug. Chem. 16, 1282-1290. doi: 10.1021/bc050201y

Sun, Y., Zeng, X., Xiao, Y., Liu, C., Zhu, H., Zhou, H., et al. (2018). Novel dualfunction near-infrared II fluorescence and PET probe for tumor delineation and image-guided surgery. Chem. Sci. 9, 2092-2097. doi: 10.1039/C7SC04774F

Szabó, Á., Szendi-Szatmári, T., Ujlaky-Nagy, L., Rádi, I., Vereb, G., Szöllosi, J., et al. (2018). The effect of fluorophore conjugation on antibody affinity and the photophysical properties of dyes. Biophys. J. 114, 688-700. doi: 10.1016/j.bpj.2017.12.011

Tarazi, L., George, A., Patonay, G., and Strekowski, L. (1998). Spectral characterization of a novel near-infrared cyanine dye: a study of its complexation with metal ions. Talanta 46, 1413-1424. doi: 10.1016/S0039-9140(98)00012-5

Terwisscha van Scheltinga, A. G., van Dam, G. M., Nagengast, W. B., Ntziachristos, V., Hollema, H., Herek, J. L., et al. (2011). Intraoperative near-infrared fluorescence tumor imaging with vascular endothelial growth factor and human epidermal growth factor receptor 2 targeting antibodies. J. Nucl. Med. 52, 1778-1785. doi: 10.2967/jnumed.111.092833

Toseland, C. P. (2013). Fluorescent labeling and modification of proteins. J. Chem. Biol. 6, 85-95. doi: 10.1007/s12154-013-0094-5

Tringale, K. R., Pang, J., and Nguyen, Q. T. (2018). Image-guided surgery in cancer: a strategy to reduce incidence of positive surgical margins. Wiley Interdiscip. Rev. Syst. Biol. Med. 10, 1-18. doi: 10.1002/wsbm.1412

Tsai, W. K., Zettlitz, K. A., Tavaré, R., Kobayashi, N., Reiter, R. E., and Wu, A. M. (2018). Dual-modality immunoPET/fluorescence imaging of prostate cancer with an anti-PSCA Cys-minibody. Theranostics 8, 5903-5914. doi: 10.7150/thno.27679

Tummers, Q. R., Hoogstins, C. E., Gaarenstroom, K. N., de Kroon, C. D., van Poelgeest, M. I., Vuyk, J., et al. (2016). Intraoperative imaging of folate receptor alpha positive ovarian and breast cancer using the tumor specific agent. EC17 Oncotarget. 7:8282. doi: 10.18632/oncotarget.8282

Tummers, Q. R., Hoogstins, C. E., Peters, A. A., De Kroon, C. D., Trimbos, J. B., Van De Velde, C. J., et al. (2015). The value of intraoperative near-infrared fluorescence imaging based on enhanced permeability and retention of indocyanine green: feasibility and false-positives in ovarian cancer. PLOS ONE 10:e0129766. doi: 10.1371/journal. pone.0129766

Tummers, W. S., Kimura, R. H., Abou-Elkacem, L., Beinat, C., Vahrmeijer, A. L., Swijnenburg, R.-J., et al. (2018a). Development and preclinical validation of a cysteine knottin peptide targeting integrin $\alpha v \beta 6$ for near-infrared fluorescent-guided surgery in pancreatic cancer. Clin. Cancer Res. Clincanres 24, 1667-1676. doi: 10.1158/1078-0432.CCR-17-2491

Tummers, W. S., Miller, S. E., Teraphongphom, N. T., Gomez, A., Steinberg, I., Huland, D. M., et al. (2018b). Intraoperative pancreatic cancer detection using tumor-specific multimodality molecular imaging. Ann. Surg. Oncol. 25, 1880-1888. doi: 10.1245/s10434-018-6453-2
Ueo, H., Shinden, Y., Tobo, T., Gamachi, A., Udo, M., Komatsu, H., et al. (2015). Rapid intraoperative visualization of breast lesions with $\gamma$-glutamyl hydroxymethyl rhodamine green. Sci. Rep. 5:12080. doi: 10.1038/srep12080

Unkart, J. T., Chen, S. L., Wapnir, I. L., González, J. E., Harootunian, A., and Wallace, A. M. (2017). Intraoperative tumor detection using a ratiometric activatable fluorescent peptide: a first-in-human phase 1 study. Ann. Surg. Oncol. 24, 3167-3173. doi: 10.1245/s10434-017-5991-3

Urano, Y., Sakabe, M., Kosaka, N., and Ogawa, M. (2011). Rapid cancer detection by topically spraying a $\gamma$-glutamyltranspeptidase - activated fluorescent probe. Cancer Imaging 3:110ra1 19. doi: 10.1126/scitranslmed.3002823

Van Brussel, A. S., Adams, A., Vermeulen, J. F., Oliveira, S., Van Der Wall, E., Mali, W. P., et al. (2013). Molecular imaging with a fluorescent antibody targeting carbonic anhydrase IX can successfully detect hypoxic ductal carcinoma in situ of the breast. Breast Cancer Res. Treat. 140, 263-272. doi: 10.1007/s10549-013-2635-6

van Dam, G. M., Themelis, G., Crane, L. M. A., Harlaar, N. J., Pleijhuis, R. G., Kelder, W., et al. (2011). Intraoperative tumor-specific fluorescence imaging in ovarian cancer by folate receptor- $\alpha$ targeting: first in-human results. Nat. Med. 17, 1315-1319. doi: 10.1038/nm.2472

Van Der Vorst, J. R., Schaafsma, B. E., Hutteman, M., Verbeek, F. P., Liefers, G. J., Hartgrink, H. H., et al. (2013). Near-infrared fluorescence-guided resection of colorectal liver metastases. Cancer 119, 3411-3418. doi: 10.1002/cncr.28203

van Driel, P. B., Boonstra, M. C., Prevoo, H. A., van de Giessen, M. Snoeks, T. J., Tummers, Q. R., et al. (2016). EpCAM as multi-tumour target for near-infrared fluorescence guided surgery. BMC Cancer 16:884. doi: 10.1186/s12885-016-2932-7

Van Driel, P. B., Van Der Vorst, J. R., Verbeek, F. P., Oliveira, S., Snoeks, T. J., Keereweer, S., et al. (2014). Intraoperative fluorescence delineation of head and neck cancer with a fluorescent Anti-epidermal growth factor receptor nanobody. Int. J. Cancer 134, 2663-2673. doi: 10.1002/ijc.28601

van Keulen, S., van den Berg, N. S., Nishio, N., Birkeland, A., Zhou, Q., Lu, G., et al. (2019). Rapid, non-invasive fluorescence margin assessment: Optical specimen mapping in oral squamous cell carcinoma. Oral. Oncol. 88, 58-65. doi: 10.1016/j.oraloncology.2018.11.012

Van Leeuwen, F., Valdés-Olmos, R., Buckle, T., and Vidal-Sicart, S. (2016). Hybrid surgical guidance based on the integration of radionuclear and optical technologies. Br. J. Radiol. 89:20150797. doi: 10.1259/bjr.20150797

van Manen, L., Handgraaf, H. J. M., Diana, M., Dijkstra, J., Ishizawa, T., Vahrmeijer, A. L., et al. (2018). A practical guide for the use of indocyanine green and methylene blue in fluorescence-guided abdominal surgery. J. Surg. Oncol. 118, 283-300. doi: 10.1002/jso.25105

van Oosten, M., Crane, L. M., Bart, J., van Leeuwen, F. W., and van Dam, G. M. (2011). Selecting potential targetable biomarkers for imaging purposes in colorectal cancer using target selection criteria (TASC): a novel target identification tool. Transl. Oncol. 4, 71-82. doi: 10.1593/tlo.10220

Veiseh, M., Gabikian, P., Bahrami, S. B., Veiseh, O., Zhang, M., Hackman, R. C., et al. (2007). Tumor paint: a chlorotoxin:Cy5.5 bioconjugate for intraoperative visualization of cancer foci. Cancer Res. 67, 6882-6888. doi: 10.1158/0008-5472.CAN-06-3948

Verbeek, F. P., van der Vorst, J. R., Tummers, Q. R., Boonstra, M. C., de Rooij, K. E., Löwik, C. W., et al. (2014). Near-infrared fluorescence imaging of both colorectal cancer and ureters using a low-dose integrin targeted probe. Ann. Surg. Oncol. 21, 528-537. doi: 10.1245/s10434-014-3524-x

Vira, S., Mekhedov, E., Humphrey, G., and Blank, P. S. (2010). Fluorescent-labeled antibodies: balancing functionality and degree of labeling. Anal. Biochem. 402, 146-150. doi: 10.1016/j.ab.2010.03.036

Walker, E., Mann, M., Honda, K., Vidimos, A., Schluchter, M. D., Straight, B., et al. (2017). Rapid visualization of nonmelanoma skin cancer. J. Am. Acad. Dermatol. 76, 209-216.e9. doi: 10.1016/j.jaad.2016.09.008

Wang, X., Huang, S. S., Heston, W. D., Guo, H., Wang, B.-C., and Basilion, J. P. (2014). Development of targeted near-infrared imaging agents for prostate cancer. Mol. Cancer Ther. 13, 2595-2606. doi: 10.1158/1535-7163.MCT-14-0422

Warram, J. M., De Boer, E., Korb, M., Hartman, Y., Kovar, J., Markert, J. M., et al. (2015). Fluorescence-guided resection of experimental malignant glioma using cetuximab-IRDye 800CW. Br. J. Neurosurg. 29, 850-858. doi: 10.3109/02688697.2015.1056090 
Warram, J. M., de Boer, E., van Dam, G. M., Moore, L. S., Bevans, S. L., Walsh, E. M., et al. (2016). Fluorescence imaging to localize head and neck squamous cell carcinoma for enhanced pathological assessment. J. Pathol. Clin. Res. 2, 104-112. doi: 10.1002/cjp2.40

Watanabe, R., Sato, K., Hanaoka, H., Harada, T., Nakajima, T., Kim, I., et al. (2014). Minibody-indocyanine green based activatable optical imaging probes: the role of short polyethylene glycol linkers. ACS Med. Chem. Lett. 5, 411-415. doi: $10.1021 / \mathrm{ml} 400533 y$

Wayua, C., and Low, P. S. (2014). Evaluation of a cholecystokinin 2 receptortargeted near-infrared dye for fluorescence-guided surgery of cancer. Mol. Pharm. 11, 468-476. doi: 10.1021/mp400429h

Weissleder, R., and Ntziachristos, V. (2003). Shedding light onto live molecular targets. Nat. Med. 9, 123-128. doi: 10.1038/nm0103-123

Whitley, M. J., Cardona, D. M., Lazarides, A. L., Spasojevic, I., Ferrer, J. M., Cahill, J., et al. (2016). A mouse-human phase 1 co-clinical trial of a proteaseactivated fluorescent probe for imaging cancer. Sci. Transl. Med. 8:320ra4320ra4. doi: 10.1126/scitranslmed.aad0293

Xenaki, K. T., Oliveira, S., and van Bergen en Henegouwen, P. M. P. (2017). Antibody or antibody fragments: implications for molecular imaging and targeted therapy of solid tumors. Front. Immunol. 8:1287. doi: 10.3389/fimmu.2017.01287

Xu, H., Bandari, R. P., Lee, L., Li, R., Yu, P., Smith, C. J., et al. (2018). Design, synthesis, and in vitro and in vivo evaluation of high affinity and specificity near-infrared fluorescent bombesin antagonists for tumor imaging. J. Med. Chem. 61, 7657-7670. doi: 10.1021/acs.jmedchem.8b00614

Yang, L., Sajja, H. K., Cao, Z., Qian, W., Bender, L., Marcus, A. I., et al. (2014). uPAR-targeted optical imaging contrasts as theranostic agents for tumor margin detection. Theranostics 4, 106-118. doi: 10.7150/thno.7409

Yang, Z., Usama, S. M., Li, F., Burgess, K., and Li, Z. (2018). A Zwitterionic nearinfrared dye linked TrkC targeting agent for imaging metastatic breast cancer. Medchemcomm 9, 1754-1760. doi: 10.1039/C8MD00190A

Yi, X., Wang, F., Qin, W., Yang, X., and Yuan, J. (2014). Near-infrared fluorescent probes in cancer imaging and therapy: an emerging field. Int. J. Nanomedicine 9, 1347-1365. doi: 10.2147/IJN.S60206

Zettlitz, K. A., Tsai, W. T. K., Knowles, S. M., Kobayashi, N., Donahue, T. R., Reiter, R. E., et al. (2018). Dual-modality immunoPET and near-infrared fluorescence (NIRF) imaging of pancreatic cancer using an anti-prostate cancer stem cell antigen (PSCA) cys-diabody. J. Nucl. Med. 59:1398-1405. doi: $10.2967 /$ jnumed.117.207332
Zettlitz, K. A., Waldmann, C. M., Tsai, W. K., Tavaré, R., Collins, J., Murphy, J. M., et al. (2019). A dual-modality linker enables site-specific conjugation of antibody fragments for $18 \mathrm{~F}$-immunoPET and fluorescence imaging. J. Nucl. Med. doi: 10.2967/jnumed.118.223560. [Epub ahead of print].

Zhang, H., Desai, P., Koike, Y., Houghton, J., Carlin, S., Tandon, N., et al. (2017a). Dual-modality imaging of prostate cancer with a fluorescent and radiogalliumlabeled gastrin-releasing peptide receptor antagonist. J. Nucl. Med. 58, 29-35. doi: 10.2967/jnumed.116.176099

Zhang, M., Kobayashi, N., Zettlitz, K. A., Kono, E. A., Yamashiro, J. M., Tsai, W. K., et al. (2018). Near-infrared-dye labeled anti-prostate stem cell antigen minibody enables real-time fluorescence imaging and targeted surgery in translational mouse models. Clin. Cancer Res. 25:1382.2018. doi: 10.1158/1078-0432.CCR-18-1382

Zhang, R. R., Schroeder, A. B., Grudzinski, J. J., Rosenthal, E. L., Warram, J. M., Pinchuk, A. N., et al. (2017b). Beyond the margins: real-time detection of cancer using targeted fluorophores. Nat. Rev. Clin. Oncol. 14, 347-364. doi: 10.1038/nrclinonc.2016.212

Zhu, B., Wu, G., Robinson, H., Wilganowski, N., Hall, M. A., Ghosh, S. C., et al. (2013). Tumor margin detection using quantitative NIRF molecular imaging targeting EpCAM validated by far red gene reporter iRFP. Mol. Imaging Biol. 15, 560-568. doi: 10.1007/s11307-013-0637-8

Zielinski, R., Hassan, M., Lyakhov, I., Needle, D., Chernomordik, V., GarciaGlaessner, A., et al. (2012). Affibody-dylight conjugates for in vivo assessment of HER2 expression by near-infrared optical imaging. PLoS ONE 7:e41016. doi: 10.1371/journal.pone.0041016

Conflict of Interest Statement: SH holds a patent in camelid single-domain diagnostics and therapeutics.

The remaining author declares that the research was conducted in the absence of any commercial or financial relationships that could be construed as a potential conflict of interest.

Copyright (c) 2019 Debie and Hernot. This is an open-access article distributed under the terms of the Creative Commons Attribution License (CC BY). The use, distribution or reproduction in other forums is permitted, provided the original author(s) and the copyright owner(s) are credited and that the original publication in this journal is cited, in accordance with accepted academic practice. No use, distribution or reproduction is permitted which does not comply with these terms. 